\title{
Design and Synthesis of Pyrankacin: A Pyranmycin Class Broad Spectrum Aminoglycoside Antibiotic
}

\author{
Ravi Rai, Hsiao-Nung Chen, Przemyslaw G. Czyryca, Jie Li, and \\ Cheng-Wei Tom Chang \\ Department of Chemistry and Biochemistry, Utah State University, 0300 Old \\ Main Hill, Logan, UT 84322-0300
}

Tel: +4357973545. Fax:+4357973390. Email: chang@cc.usu.edu

\section{Supporting Information}

I. Experimental Section (S2 - S7)

II. ${ }^{1} \mathrm{H},{ }^{13} \mathrm{C}$, and COSY Spectra (S8 - S27)

III. Molecular Modeling of Pyrankacin (S28 - S30)

IV. References (S31) 


\section{Experimental Section}

Proton magnetic resonance spectra were recorded using a Jeol 270 or Bruker 400 spectrometers. Chemical shifts were reported as parts per million (ppm) downfield from tetramethylsilane in $\delta$ unit, and coupling constants were given in cycles per second $(\mathrm{Hz})$. Splitting patterns were designed as s, singlet; $d$, doublet; $t$, triplet; q, quartet; m, multiplet. ${ }^{13} \mathrm{C}$ spectra were obtained using the Jeol 270 spectrometer at $68 \mathrm{MHz}$ or Bruker 400 spectrometers at $100 \mathrm{MHz}$. Routine 13C NMR spectra were fully decoupled by broad-band waltz decoupling. All NMR spectra were recorded at ambient temperature unless otherwise noted. Low-resolution fast-atom bombardment (LRFAB) and High-resolution fast-atom bombardment (HRFAB) or High-resolution MALDI were provided by the Mass Spectrometry Facilities, University of California, Riverside.

Chemical reagents and starting materials were purchased from Aldrich Chemical Co. or Acros Chemical Co. and were used without purification unless otherwise noted. Dichloromethane was distilled over $\mathrm{CaH}_{2}$. Other solvents were used without purification.

\section{3',4'-Di-O-benzyl-1,3,2',6'-tetraazidoneamine (1)}

\section{$1,3,2$ ',6'-tetraazido-3',4'-dideoxy-3'-enoneamine $(2)^{2}$}

\section{5,6-Di-O-(4-chlorobenzoyl)-1,3,2',6'-tetraazido-3',4'-dideoxy-3'-enoneamine (3).}

The diol, $2(0.30 \mathrm{~g}, 0.76 \mathrm{mmol})$ was dissolved in anhydrous $\mathrm{CH}_{2} \mathrm{Cl}_{2}$ and to this was added $\mathrm{Et}_{3} \mathrm{~N}(0.85 \mathrm{~mL}, 6.1 \mathrm{mmol})$, catalytic amount of DMAP followed by 4-chlorobenzoyl chloride (0.58 mL, $4.5 \mathrm{mmol})$. This mixture was stirred for $48 \mathrm{hrs}$ at R.T. After the reaction was complete, the reaction was quenched by $\mathrm{NaHCO}_{3(\mathrm{~s})}$ and filtered through a column packed with Celite and silica gel. This was then washed with $1 \mathrm{~N} \mathrm{HCl}_{(\mathrm{aq})}$, saturated $\mathrm{NaHCO}_{3(\mathrm{aq})}, \mathrm{H}_{2} \mathrm{O}$, and brine, then dried over $\mathrm{Na}_{2} \mathrm{SO}_{4(\mathrm{~s})}$. After removal of the solvent followed by purification with a gradient column chromatography (Hexane: EtOAc $=100: 0$ to 60: 40), the product was obtained as a white solid (0.42 g, $0.62 \mathrm{mmol}, 82 \%) .{ }^{1} \mathrm{H} \mathrm{NMR}\left(400 \mathrm{MHz}, \mathrm{CDCl}_{3}\right) \delta 7.2-$ 
$7.8(\mathrm{~m}, 8 \mathrm{H}), 5.90(\mathrm{dt}, J=10.5 \mathrm{~Hz}, J=2.0 \mathrm{~Hz}, 1 \mathrm{H}), 5.80(\mathrm{dq}, J=10.4 \mathrm{~Hz}, J=2.0 \mathrm{~Hz}, 1 \mathrm{H}), 5.58$ (dd, $J=9.9 \mathrm{~Hz}, J=9.8 \mathrm{~Hz}, 1 \mathrm{H}, \mathrm{H}-5), 5.32$ (dd, $J=10.1 \mathrm{~Hz}, J=10.1 \mathrm{~Hz}, 1 \mathrm{H}, \mathrm{H}-6), 5.26$ (d, $J$ $\left.=4.1 \mathrm{~Hz}, 1 \mathrm{H}, \mathrm{H}-1^{\prime}\right), 4.80$ (m, 1H, H-5'), 3.96 (dd, $\left.J=9.7 \mathrm{~Hz}, J=9.7 \mathrm{~Hz}, 1 \mathrm{H}, \mathrm{H}-4\right), 3.78$ (ddd, $J=12.4 \mathrm{~Hz}, J=10.1 \mathrm{~Hz}, J=4.6 \mathrm{~Hz}, 1 \mathrm{H}, \mathrm{H}-1), 3.57$ (ddd, $J=9.8 \mathrm{~Hz}, J=2.6 \mathrm{~Hz}, J=12.4$ Hz, 1H, H-3), 3.44 ( ddd, $J=9.2 \mathrm{~Hz}, J=3.7 \mathrm{~Hz}, J=3.8 \mathrm{~Hz}, 2 \mathrm{H}, \mathrm{H}-2^{\prime}, \mathrm{H}-6$ '), 3.27 (dd, $J=$ $5.7 \mathrm{~Hz}, J=5.7 \mathrm{~Hz}, 1 \mathrm{H}, \mathrm{H}-6$ '), 2.50 (ddd, $J=13.4 \mathrm{~Hz}, J=13.4 \mathrm{~Hz}, J=13.4 \mathrm{~Hz}, 1 \mathrm{H}, \mathrm{H}-2_{\text {eq }}$ ), 1.82 (ddd, $\left.J=13.3 \mathrm{~Hz}, J=12.6 \mathrm{~Hz}, J=12.5 \mathrm{~Hz}, 1 \mathrm{H}, \mathrm{H}-2_{\mathrm{ax}}\right) \cdot{ }^{13} \mathrm{C} \mathrm{NMR}\left(100 \mathrm{MHz}, \mathrm{CDCl}_{3}\right)$ $\delta 164.1(\mathrm{~s}), 163.8(\mathrm{~s}), 139.6(\mathrm{~s}), 139.5$ (s), $130.6(\mathrm{~s}), 130.3$ (s), 128.7 (s), $128.4(\mathrm{~s}), 128.3(\mathrm{~s})$, $126.7(\mathrm{~s}), 126.3$ (s), 97.4 (s), 77.2 (s), 73.7 (s), 73.6 (s), 58.7 (s), 57.5 (s), 53.7 (s), 53.5 (s), $31.8(\mathrm{~s}), 29.1(\mathrm{~s}), 13.6(\mathrm{~s})$; mass spec sample submitted.

\section{5,6-Di-O-(4-chlorobenzoyl)-1-N-tert-butoxycarbonyl-3,2',6'-triazido-3',4'-dideoxy-3'-}

enoneamine (4). To a solution of the di-acylated compound, $3(0.20 \mathrm{~g}, 0.29 \mathrm{mmol})$, BOC-ON $(0.17 \mathrm{~g}, 0.71 \mathrm{mmol})$ in $10 \mathrm{~mL}$ anhydrous toluene at $-78^{\circ} \mathrm{C}$ under nitrogen, $\mathrm{PMe}_{3}(1.0 \mathrm{M}$ solution in toluene) $(0.32 \mathrm{~mL}, 0.32 \mathrm{mmol})$ was added. The reaction was kept at $-78^{\circ} \mathrm{C}$ for 30 minutes, then was allowed to warm to $-10^{\circ} \mathrm{C}$. The reaction was quenched with phophate buffer $(\mathrm{pH}=7.4)$ and was concentrated. The residue was extracted with EtOAc. The organic layer was washed with $1 \mathrm{~N} \mathrm{HCl}_{(\mathrm{aq})}, \mathrm{H}_{2} \mathrm{O}$, saturated $\mathrm{NaHCO}_{3(\mathrm{aq})}$, and brine, then dried over $\mathrm{Na}_{2} \mathrm{SO}_{4(\mathrm{~s})}$. Removal of the solvent followed by purification with gradient column chromatography (Hexanes:EtOAc $=100: 0$ to $40: 60)$ afforded the desired product $(0.11 \mathrm{~g}$, $0.14 \mathrm{mmol}, 84 \%) .{ }^{1} \mathrm{H}$ NMR (400 MHz, $\left.\mathrm{CDCl}_{3}\right) \delta 7.2-7.8(\mathrm{~m}, 8 \mathrm{H}), 5.8(\mathrm{~d}, J=10.5 \mathrm{~Hz}, 1 \mathrm{H}$, H-3'), 5.7 (d, $J=10.5 \mathrm{~Hz}, 1 \mathrm{H}, \mathrm{H}-4$ '), 5.6 (dd, $J=9.7 \mathrm{~Hz}, J=9.7 \mathrm{~Hz}, 1 \mathrm{H}, \mathrm{H}-5$ ), 5.27 (d, $J=$ $\left.5.6 \mathrm{~Hz}, 1 \mathrm{H}, \mathrm{H}-\mathrm{1}^{\prime}\right), 5.1$ (dd, $\left.J=10.2 \mathrm{~Hz}, J=10.3 \mathrm{~Hz}, 1 \mathrm{H}, \mathrm{H}-6\right), 4.6-4.8$ (m, 1H, H-5), 3.92 (dd, $J=9.6 \mathrm{~Hz}, J=9.7 \mathrm{~Hz}, 1 \mathrm{H}, \mathrm{H}-4$ ), 3.72 (dd, $J=6.4 \mathrm{~Hz}, J=5.8 \mathrm{~Hz}, 1 \mathrm{H}, \mathrm{H}-1$ ), 3.43 (ddd, $\left.J=3.4 \mathrm{~Hz}, J=9.0 \mathrm{~Hz}, J=3.7 \mathrm{~Hz}, 1 \mathrm{H}, \mathrm{H}-2^{\prime}\right), 3.26(\mathrm{ddd}, J=5.7 \mathrm{~Hz}, J=12.8 \mathrm{~Hz}, J=7.1 \mathrm{~Hz}$, 1H, H-6'), 2.53 (ddd, $J=13.1 \mathrm{~Hz}, J=4.3 \mathrm{~Hz}, J=4.0 \mathrm{~Hz}, 1 \mathrm{H}, \mathrm{H}-2_{\text {eq }}$ ), 1.62 (ddd, $J=12.7$ $\left.\mathrm{Hz}, J=12.8 \mathrm{~Hz}, J=12.5 \mathrm{~Hz}, 1 \mathrm{H}, \mathrm{H}-2_{\mathrm{ax}}\right), 1.24(\mathrm{~s}, 9 \mathrm{H}) .{ }^{13} \mathrm{C} \mathrm{NMR}\left(100 \mathrm{MHz}, \mathrm{CDCl}_{3}\right) \delta 165.8$ (s), 164.2 (s), 155.0 (s), 140.2 (s, 2 carbons), 139.9 (s), 131.4 (s, 2 carbons), 130.9 (s), 129.3 (s), 129.0 (s), 128.8 (s), 127.6 (s), 127.0 (s), 122.9 (s), 98.1 (s), 80.3 (s), 78.4 (s), 77.5 (s), $77.0(\mathrm{~s}), 76.6(\mathrm{~s}), 74.5(\mathrm{~s}), 74.3(\mathrm{~s}), 68.8(\mathrm{~s}), 68.0(\mathrm{~s}), 59.6(\mathrm{~s}), 54.3$ (s), $54.0(\mathrm{~s}), 33.6(\mathrm{~s})$, 
28.1 (s), 25.6 (s). MALDI Calcd for $\mathrm{C}_{31} \mathrm{H}_{32} \mathrm{Cl}_{2} \mathrm{~N}_{10} \mathrm{O}_{8} \mathrm{Na}\left([\mathrm{M}+\mathrm{Na}]^{+}\right)$m/e 765.1674; measure $\mathrm{m} / \mathrm{e} 765.1655$.

1-N-tert-butoxycarbonyl-3,2',6'-triazido-3',4'-dideoxy-3'-enoneamine (5). To a solution of compound $4(0.57 \mathrm{~g}, 0.76 \mathrm{mmol})$ in $5 \mathrm{~mL}$ THF and $\mathrm{H}_{2} \mathrm{O}(3: 1)$ at $0^{\circ} \mathrm{C}$, lithium hydroxide monohydrate $(0.19 \mathrm{~g}, 4.5 \mathrm{mmol})$ was added. The reaction mixture was stirred overnight allowing the reaction temperature to warm to room temperature. The reaction was carefully concentrated then diluted with EtOAc. The organic solution washed with water and brine then dried over $\mathrm{Na}_{2} \mathrm{SO}_{4(\mathrm{~s})}$. Removal of the solvent followed by purification with gradient column chromatography (Hexanes:EtOAc $=70: 30$ to 30:70) yielded the desired product (0.27 g, $0.66 \mathrm{mmol}, 87 \%) .{ }^{1} \mathrm{H}$ NMR $\left(400 \mathrm{MHz}, \mathrm{CDCl}_{3}\right) \delta 5.8-5.9(\mathrm{~m}, 2 \mathrm{H}), 5.6(\mathrm{~d}, J=4.0 \mathrm{~Hz}$, 1H, H-1'), 4.73(m, 1H), 4.6 (d, $J=6.6 \mathrm{~Hz}, 1 \mathrm{H}), 4.52$ (d, $J=3.9 \mathrm{~Hz}, 1 \mathrm{H}), 4.1$ (m, 1H), 4.0 (m, 1H), $3.2-3.5$ (m, 7H), 2.41 (ddd, $J=12.9 \mathrm{~Hz}, J=3.7 \mathrm{~Hz}, J=3.7 \mathrm{~Hz}, 1 \mathrm{H}, \mathrm{H}-2_{\mathrm{eq}}$ ), 1.43 (s, 9H), 1.26 (m, 1H, H-2ax). ${ }^{13} \mathrm{C}$ NMR (100 MHz, $\left.\mathrm{CDCl}_{3}\right) \delta 129.6$ (s), 122.9 (s), 99.8 (s), 97.5 (s), $81.6(\mathrm{~s}), 76.4(\mathrm{~s}), 75.9(\mathrm{~s}), 68.9(\mathrm{~s}), 60.2(\mathrm{~s}), 59.9(\mathrm{~s}), 55.9(\mathrm{~s}), 55.6(\mathrm{~s}), 54.0(\mathrm{~s}), 53.7(\mathrm{~s})$, 33.5 (s), 28.57 (s) 28.50 (s). HRFAB Calcd for $\mathrm{C}_{17} \mathrm{H}_{26} \mathrm{~N}_{10} \mathrm{O}_{6} \mathrm{Na}\left([\mathrm{M}+\mathrm{Na}]^{+}\right) \mathrm{m} / \mathrm{e}$ 765.1674; measure $\mathrm{m} / \mathrm{e} 765.1655$.

6-O-Benzoyl-1- $N$-tert-butoxycarbonyl-3,2',6'-triazido-3',4'-dideoxy-3'-enoneamine (6). To a solution of $5(0.22 \mathrm{~g}, 0.47 \mathrm{mmol})$ and DIPEA $(0.11 \mathrm{~mL}, 0.66 \mathrm{mmol})$ in anhydrous $\mathrm{CH}_{2} \mathrm{Cl}_{2}(20 \mathrm{~mL}), \mathrm{BzCl}(0.060 \mathrm{~mL}, 0.56 \mathrm{mmol})$ were added at $-50^{\circ} \mathrm{C}$. The reaction mixture was stirred for several hours allowing the reaction temperature to warm up to $0^{\circ} \mathrm{C}$. After completion of the reaction (monitored by TLC, EtOAc: Hexane = 35: 65), the reaction was then quenched with $\mathrm{NaHCO}_{3(\mathrm{~s})}$. After removal of the solvent, the reaction mixture was

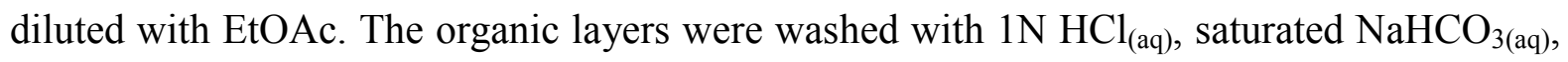
and brine, then dried over $\mathrm{Na}_{2} \mathrm{SO}_{4(\mathrm{~s})}$. Removal of the solvent followed by purification with gradient column chromatography (Hexanes:EtOAc $=100: 0$ to 60:40) afforded the product 6 (0.22 g, $0.38 \mathrm{mmol}, 99 \%) .{ }^{1} \mathrm{H}$ NMR (400 MHz, $\left.\mathrm{CDCl}_{3}\right) \delta 8.04-8.06(\mathrm{~m}, 2 \mathrm{H}), 7.4-$ $7.5(\mathrm{~m}, 3 \mathrm{H}), 5.8-5.9(\mathrm{~m}, 2 \mathrm{H}), 5.57$ (d, $\left.J=4.0 \mathrm{~Hz}, 1 \mathrm{H}, \mathrm{H}-1^{\prime}\right), 4.97$ (dd, $J=10.4 \mathrm{~Hz}, J=9.8$ $\mathrm{Hz}, 1 \mathrm{H}), 4.76(\mathrm{~m}, 1 \mathrm{H}), 4.64(\mathrm{~d}, J=8.4 \mathrm{~Hz}, 1 \mathrm{H}), 4.0(\mathrm{dd}, J=1.7 \mathrm{~Hz}, J=3.4 \mathrm{~Hz}, 1 \mathrm{H}), 3.8-3.9$ 
(m, 2H), $3.2-3.6(\mathrm{~m}, 5 \mathrm{H}), 2.43\left(\mathrm{ddd}, J=13.2 \mathrm{~Hz}, J=3.9 \mathrm{~Hz}, J=3.9 \mathrm{~Hz}, 1 \mathrm{H}, \mathrm{H}-2_{\text {eq }}\right), 1.53$ (m, 1H, H-2 ax), 1.23 (s, 9H). $\left.{ }^{13} \mathrm{C} \mathrm{NMR} \mathrm{(100} \mathrm{MHz,} \mathrm{CDCl}_{3}\right) \delta 167.2(\mathrm{~s}), 155.2(\mathrm{~s}), 132.9(\mathrm{~s})$, $129.5(\mathrm{~s}), 128.9(\mathrm{~s}), 128.6(\mathrm{~s}), 127.9(\mathrm{~s}), 122.1(\mathrm{~s}), 111.1(\mathrm{~s}), 97.2(\mathrm{~s}), 82.0(\mathrm{~s}), 78.1(\mathrm{~s}), 75.2$ (s), $74.5(\mathrm{~s}), 68.2(\mathrm{~s}), 58.9(\mathrm{~s}), 55.0(\mathrm{~s}), 53.3(\mathrm{~s}), 48.3(\mathrm{~s}), 33.2(\mathrm{~s}), 29.1(\mathrm{~s}), 27.5(\mathrm{~s}), 20.1(\mathrm{~s})$, 13.5 (s). FAB Calcd for $\mathrm{C}_{24} \mathrm{H}_{30} \mathrm{~N}_{10} \mathrm{O}_{7} \mathrm{Na}\left([\mathrm{M}+\mathrm{Na}]^{+}\right)$m/e 593.2196; measure m/e 593.2183.

\section{5-O-(4-Azido-4,6-dideoxy-ß-D-glucopyranosyl)-1- $N$-tert-butoxycarbonyl-3,2',6'-}

triazido-3',4'-dideoxy-3'-enoneamine (8). The glycosyl donor, 7 (0.71 g, $1.63 \mathrm{mmol})$, and the glycosyl acceptor, $6(0.78 \mathrm{~g}, 1.36 \mathrm{mmol})$ were dissolved in anhydrous $\mathrm{CH}_{2} \mathrm{Cl}_{2}$. To this

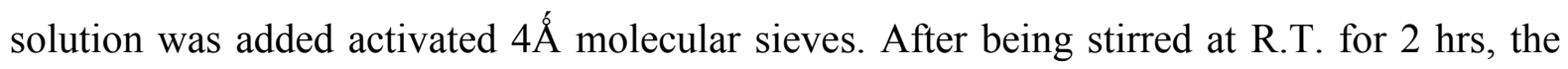
reaction mixture was cooled to $-60^{\circ} \mathrm{C}$ then catalytic amount of $\mathrm{BF}_{3}-\mathrm{OEt}_{2}$ was added. The reaction was stirred overnight. After completion of the reaction (monitored by TLC, Hexane:EtOAC $=3 / 1)$, the reaction was quenched by addition of $\mathrm{NaHCO}_{3(\mathrm{~s})}$, then filtered through Celite. Removal of the solvent followed by purification with gradient column chromatography gave the desired trisaccharide $(1.13 \mathrm{~g}, 1.36 \mathrm{mmol})$. This trisaccharide was dissolved in anhydrous $\mathrm{MeOH} / \mathrm{THF}(10 \mathrm{~mL} / 2 \mathrm{~mL})$ and NaOMe $(0.5 \mathrm{M}, 4.45 \mathrm{~mL}, 2.22 \mathrm{mmol})$ was added. The reaction mixture was stirred at room temperature till the complete consumption of starting material (ca. 2 hours, monitored by TLC, EtOAc: Hexane = 50: 50). The reaction was quenched by addition of Amberlite IR-120 $\left(\mathrm{H}^{+}\right)$then filtered through Celite. Removal of solvent followed by purification with a gradient column chromatography (Hexanes : EtOAc $=70: 30$ to 30:70) generated compound 8 (0.66 g, $1.03 \mathrm{mmol}, 63 \%) .{ }^{1} \mathrm{H}$ NMR (400 MHz, $\left.\mathrm{CDCl}_{3}\right) \delta 5.8(\mathrm{~d}, J=3.4 \mathrm{~Hz}, 1 \mathrm{H}, \mathrm{H}-1$ '), $5.87-5.96(\mathrm{~m}, 2 \mathrm{H}), 4.73$ (d, $J=1.6$ $\mathrm{Hz}, 1 \mathrm{H}$ ), 4.62 (d, $J=7.7 \mathrm{~Hz}, 1 \mathrm{H}), 4.0(\mathrm{dd}, J=14.3 \mathrm{~Hz}, J=7.1 \mathrm{~Hz}, 1 \mathrm{H}), 3.2-3.6(\mathrm{~m}, 15 \mathrm{H})$, $3.02(\mathrm{dd}, J=9.5 \mathrm{~Hz}, J=9.6 \mathrm{~Hz}, 1 \mathrm{H}), 2.1$ (m, 1H, H-2 eq $), 2.01$ (m, 1H, H-2 ax $), 1.42$ (s, 9H), 1.32 (d, $J=6.0 \mathrm{~Hz}, 3 \mathrm{H}, \mathrm{H}-6$ "). ${ }^{13} \mathrm{C}$ NMR (100 MHz, $\left.\mathrm{CDCl}_{3}\right) \delta 156.2$ (s), 129.0 (s), 128.9 (s), $128.1(\mathrm{~s}), 124.9$ (s), $122.9(\mathrm{~s}), 122.8(\mathrm{~s}), 104.0(\mathrm{~s}), 96.73$ (s), 94.9 (s), 86.3 (s), $80.4(\mathrm{~s}), 76.1$ (s), $75.2(\mathrm{~s}), 74.6(\mathrm{~s}), 70.8(\mathrm{~s}), 69.4(\mathrm{~s}), 66.9(\mathrm{~s}), 59.7(\mathrm{~s}), 53.5(\mathrm{~s}), 53.0(\mathrm{~s}), 27.8(\mathrm{~s}), 17.6(\mathrm{~s})$. FAB Calcd for $\mathrm{C}_{23} \mathrm{H}_{35} \mathrm{~N}_{13} \mathrm{O}_{9} \mathrm{Na}\left([\mathrm{M}+\mathrm{Na}]^{+}\right) \mathrm{m} / \mathrm{e}$ 660.2578; measure m/e 660.2585.

\section{5-O-(4-Azido-4,6-dideoxy- $\beta$-D-glucopyranosyl)-1- $N$-[(S)-4-(benzyloxycarbonyl-amino)-}

2-hydroxybutanoyl]-3,2',6'-triazido-3',4'-dideoxy-3'-enoneamine (10). A solution of 
glycosylated compound (8) in dichloromethane was treated with $99 \%$ trifluoroacetic acid and the reaction mixture was stirred for $3 \mathrm{hrs}$ at room temperature. The reaction mixture was quenched with triethylamine and concentrated to dryness. The crude product was directly used for peptide coupling. To this was added a mixture of ( $S$ )- $N$-carbobenzyloxyl-4-amino-2hydroxybutyric acid $(9,1.08 \mathrm{~g}, 4.26 \mathrm{mmol})$ and EDC (0.80 g, $4.17 \mathrm{mmol})$, HOBT (0.56 g, $4.14 \mathrm{mmol}), \mathrm{Et}_{3} \mathrm{~N}(3 \mathrm{~mL})$ in anhydrous DMF $(5 \mathrm{~mL})$ was stirred under nitrogen at room temperature for overnight. After completion of the reaction $\left(\mathrm{R}_{\mathrm{f}}=0.8\right.$, monitored by TLC, EtOAc 100\%), the reaction mixture was concentrated and extracted with EtOAc. The organic layer was washed with $1 \mathrm{~N} \mathrm{HCl}_{(\text {aq) }}$, saturated $\mathrm{NaHCO}_{3(\mathrm{aq})}$, and brine, then dried over $\mathrm{Na}_{2} \mathrm{SO}_{4(\mathrm{~s})}$. Removal of the solvent followed by purification with gradient column chromatography (Hexanes:EtOAc $=50: 50$ to $100 \%$ EtOAc) afforded the product $(\mathbf{1 0}, 0.86 \mathrm{~g}, 1.11 \mathrm{mmol}$, 91\%). ${ }^{1} \mathrm{H}$ NMR (400 MHz, MeOH) $\delta 7.2-7.8(\mathrm{~m}, 5 \mathrm{H}), 6.05$ (d, $J=3.5 \mathrm{~Hz}, 1 \mathrm{H}, \mathrm{H}-1$ '), $5.9-$ $6.0(\mathrm{~m}, 2 \mathrm{H}), 5.0(\mathrm{~m}, 2 \mathrm{H}), 4.70$ (d, $J=7.8 \mathrm{~Hz}, 1 \mathrm{H}, \mathrm{H}-1$ ”), 4.12 (dd, $J=3.7 \mathrm{~Hz}, J=7.2 \mathrm{~Hz}, 1 \mathrm{H})$, $3.8-3.6(\mathrm{~m}, 4 \mathrm{H}), 3.60(\mathrm{dd}, J=9.9 \mathrm{~Hz}, J=8.7 \mathrm{~Hz}, 1 \mathrm{H}) 3.2-3.5(\mathrm{~m}, 10 \mathrm{H}), 3.02(\mathrm{dd}, J=9.6$ $\mathrm{Hz}, J=9.6 \mathrm{~Hz}, 1 \mathrm{H}), 2.1$ (m, 1H, H-2 eq $), 1.8-2.0$ (m, 2H), 1.45 (m, 1H, H-2 ax), 1.36 (d, $J=$ $5.9 \mathrm{~Hz}, 3 \mathrm{H}, \mathrm{H}-6$ "), $1.2-1.3$ (m, 2H). ${ }^{13} \mathrm{C}$ NMR (100 MHz, MeOH) $\delta 174.9$ (s), 157.0 (s), $136.4(\mathrm{~s}), 129.3(\mathrm{~s}), 127.6(\mathrm{~s}), 127.1(\mathrm{~s}), 126.9(\mathrm{~s}), 122.4(\mathrm{~s}), 103.8(\mathrm{~s}), 94.9(\mathrm{~s}), 85.5$ (s), 76.5 (s), $75.1(\mathrm{~s}), 74.4(\mathrm{~s}), 74.1(\mathrm{~s}), 70.2(\mathrm{~s}), 70.1(\mathrm{~s}), 68.9(\mathrm{~s}), 67.4(\mathrm{~s}), 65.6(\mathrm{~s}), 59.9$ (s), $53.6(\mathrm{~s})$, $52.5(\mathrm{~s}), 47.8(\mathrm{~s}), 46.8(\mathrm{~s}), 36.2(\mathrm{~s}), 33.6(\mathrm{~s}), 32.0$ (s), 28.8 (s), $16.8(\mathrm{~s})$. MALDI Calcd for $\mathrm{C}_{30} \mathrm{H}_{40} \mathrm{~N}_{14} \mathrm{O}_{11} \mathrm{Na}\left([\mathrm{M}+\mathrm{Na}]^{+}\right) \mathrm{m} / \mathrm{e}$ 795.2893; measure $\mathrm{m} / \mathrm{e} 795.2863$.

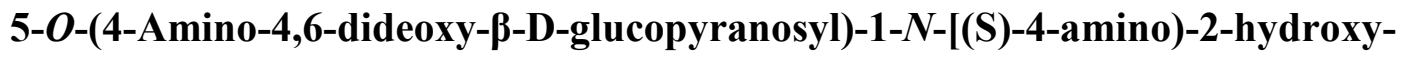

butanoyl]-3',4'-dideoxy-3'-enoneamine (Pyrankacin). To the trisaccharide $10(0.30 \mathrm{~g}$, $0.39 \mathrm{mmol})$ in THF $(5 \mathrm{~mL})$ solution in a vial equipped with a reflux condenser, $\mathrm{H}_{2} \mathrm{O}(0.5 \mathrm{~mL})$ and $\mathrm{PMe}_{3}\left(2.4 \mathrm{~mL}, 1 \mathrm{M}\right.$ in THF) were added. The reaction mixture was stirred at $50^{\circ} \mathrm{C}$ for 2 hrs. The product has a $\mathrm{R}_{\mathrm{f}}$ of 0 when eluted with $\mathrm{EtOAc} / \mathrm{MeOH}(9 / 1)$ solution and a $\mathrm{R}_{\mathrm{f}}$ of 0.9 when eluted with $i \mathrm{PrOH} / 1 \mathrm{M} \mathrm{NH}_{4} \mathrm{OAc}$ (2/1) solution. After removal of solvents, the crude perbenzylated aminoglycoside was added with catalytic amount of $\mathrm{Pd}(\mathrm{OH})_{2} / \mathrm{C}(20 \%$ Degussa type) and $5 \mathrm{~mL}$ of degassed $\mathrm{HOAc} / \mathrm{H}_{2} \mathrm{O}(1 / 3)$. After being further degassed, the reaction mixture was stirred at room temperature under atmospheric $\mathrm{H}_{2}$ pressure. After being stirred 
for 1 day, the reaction mixture was filtered through Celite. The residue was washed with water, and the combined solutions were concentrated. The crude product was purified with Amberlite CG50 $\left(\mathrm{NH}_{4}{ }^{+}\right)$eluted with a gradient of $\mathrm{NH}_{4} \mathrm{OH}$ solution $(0 \%-20 \%)$. After collection of the desired fractions and removal of solvent, the product was re-dissolved in water and loaded to an ion-exchange column packed with Dowex 1X8-200 ( $\mathrm{Cl}^{-}$form), and eluted with water. After removal of solvent, the product was obtained as white solid ( 67.2 mg, $0.125 \mathrm{mmol}, 32 \%) .{ }^{1} \mathrm{H}$ NMR (400 MHz, $\mathrm{D}_{2} \mathrm{O}$ ) (chloride salt) $\delta 5.72$ (d, J=4.0 Hz, $1 \mathrm{H}$, H-1'), 5.18 (d, $\left.J=7.8 \mathrm{~Hz}, 1 \mathrm{H}, \mathrm{H}-1^{\prime \prime}\right), 4.31$ (m, 2H), 4.0 (dd, $\left.J=7.7 \mathrm{~Hz}, J=8.9 \mathrm{~Hz}, 1 \mathrm{H}\right), 3.99$ (d, $J=7.7 \mathrm{~Hz}, 2 \mathrm{H}), 3.89$ (m, 3H), 3.70 (dd, $J=9.0 \mathrm{~Hz}, J=8.2 \mathrm{~Hz}, 1 \mathrm{H}), 3.4-3.5$ (m, 3H), $3.34(\mathrm{~d}, J=12.9 \mathrm{~Hz}, 1 \mathrm{H}), 3.22(\mathrm{~m}, 4 \mathrm{H}), 3.10(\mathrm{dd}, J=9.7 \mathrm{~Hz}, J=9.8 \mathrm{~Hz}, 1 \mathrm{H}), 2.27$ (ddd, $J$ $\left.=13.1 \mathrm{~Hz}, J=4.3 \mathrm{~Hz}, J=4.3 \mathrm{~Hz}, 1 \mathrm{H}, \mathrm{H}-2_{\mathrm{eq}}\right), 2.0(\mathrm{~m}, 1 \mathrm{H}), 1.98(\mathrm{~m}, 1 \mathrm{H}), 1.79$ (ddd, $J=11.2$ $\left.\mathrm{Hz}, J=12.3 \mathrm{~Hz}, J=13.3 \mathrm{~Hz}, 1 \mathrm{H}, \mathrm{H}-2_{\mathrm{ax}}\right), 1.46$ (d, $\left.J=6.2 \mathrm{~Hz}, 3 \mathrm{H}, \mathrm{H}-6 "\right) .{ }^{13} \mathrm{C}$ NMR (100 MHz, $\mathrm{D}_{2} \mathrm{O}$ ) (chloride salt) $\delta 175.7$ (s), 103.0 (s), 95.9 (s), 82.5 (s), 75.0 (s), 74.2 (s), 69.8 (s), 68.0 (s), 65.9 (s), 57.5, 49.8 (s), 49.3 (s), 49.2 (s), $42.8(\mathrm{~s}), 36.8$ (s), 31.1 (s), 25.8 (s), 25.2 (s), 21.2 (s), 17.1 (s). FAB Calcd for $\mathrm{C}_{22} \mathrm{H}_{45} \mathrm{~N}_{6} \mathrm{O}_{9}\left([\mathrm{M}+\mathrm{H}]^{+}\right) \mathrm{m} / \mathrm{z}$ 537.3248; measure $\mathrm{m} / \mathrm{z}$ 537.3241 .

Procedure for MIC determination. ${ }^{2}$ A soltion of selected bacteria was inoculated in the Trypticase Soy broth at $35^{\circ} \mathrm{C}$ for 1 - $2 \mathrm{hrs}$. After which, the bacteria concentration was measured, and diluted with broth, if necessary, to an absorption value of 0.08 to 0.1 at 625 $\mathrm{nm}$. The adjusted inoculated medium $(100 \mu \mathrm{L})$ was diluted with $10 \mathrm{~mL}$ broth, and then applied to a 96 -well microtilter plate $(50 \mu \mathrm{L})$. A series of solutions $(50 \mu \mathrm{L}$ each in 2 -fold dilution) of the tested compounds was added to the testing wells. The 96-well plate was incubated at $35^{\circ} \mathrm{C}$ for $12-18 \mathrm{hrs}$. The minimum inhibitory concentration (MIC) is defined as the minimum concentration of compound needed to inhibit the growth of bacteria. The MIC results are repeated at least twice. 
II. ${ }^{1} \mathrm{H},{ }^{13} \mathrm{C}$, and COSY Spectra

\begin{tabular}{|c|c|}
\hline Compound & Page \\
\hline${ }^{1} \mathrm{H}-{ }^{1} \mathrm{H}$ COSY of ${ }^{1} \mathrm{H}$ NMR of 1,3,2',6'-tetraazido-3',4'-dideoxy-3'-enoneamine (2) & S9 \\
\hline${ }^{1}$ H NMR of 5,6-Di-O-(4-chlorobenzoyl)-1,3,2',6'-tetraazido-3',4'-dideoxy-3'-enoneamine (3) & S10 \\
\hline${ }^{13} \mathrm{C}$ NMR of 5,6-Di-O-(4-chlorobenzoyl)-1,3,2',6'-tetraazido-3',4'-dideoxy-3'-enoneamine (3) & S11 \\
\hline${ }^{1} \mathrm{H}_{-}{ }^{1} \mathrm{H}$ COSYof 5,6-Di-O-(4-chlorobenzoyl)-1,3,2',6'-tetraazido-3',4'-dideoxy-3'-enoneamine (3) & S12 \\
\hline $\begin{array}{l}{ }^{1} \mathrm{H} \text { NMR of 5,6-Di-O-(4-chlorobenzoyl)-1-N-tert-butoxycarbonyl-3,2',6'-triazido-3',4'-dideoxy- } \\
\text { 3'-enoneamine (4) }\end{array}$ & S13 \\
\hline $\begin{array}{l}{ }^{13} \mathrm{C} \text { NMR of 5,6-Di-O-(4-chlorobenzoyl)-1- } N \text {-tert-butoxycarbonyl-3,2',6'-triazido-3',4'-dideoxy- } \\
\text { 3'-enoneamine (4) }\end{array}$ & S14 \\
\hline $\begin{array}{l}{ }^{1} \mathrm{H}_{-}^{1}{ }^{\mathrm{H}} \text { COSYof 5,6-Di-O-(4-chlorobenzoyl)-1- } N \text {-tert-butoxycarbonyl-3,2',6'-triazido-3',4'- } \\
\text { dideoxy-3'-enoneamine (4) }\end{array}$ & S15 \\
\hline${ }^{1}$ H NMR of 1-N-tert-butoxycarbonyl-3,2',6'-triazido-3',4'-dideoxy-3'-enoneamine (5) & S16 \\
\hline${ }^{13} \mathrm{C}$ NMR of 1-N-tert-butoxycarbonyl-3,2',6'-triazido-3',4'-dideoxy-3'-enoneamine (5) & S17 \\
\hline${ }^{1} \mathrm{H}^{1}{ }^{1} \mathrm{H}$ COSYof 1-N-tert-butoxycarbonyl-3,2',6'-triazido-3',4'-dideoxy-3'-enoneamine (5) & S18 \\
\hline $\begin{array}{l}{ }^{1} \mathrm{H} \text { NMR of 6-O-Benzoyl-1- } N \text {-tert-butoxycarbonyl-3,2',6'-triazido-3',4'-dideoxy-3'-enoneamine } \\
\text { (6) }\end{array}$ & S19 \\
\hline $\begin{array}{l}{ }^{13} \mathrm{C} \text { NMR of 6-O-Benzoyl-1- } N \text {-tert-butoxycarbonyl-3,2',6'-triazido-3',4'-dideoxy-3'-enoneamine } \\
\text { (6) }\end{array}$ & S20 \\
\hline $\begin{array}{l}{ }^{1} \mathrm{H}-{ }^{1} \mathrm{H} \text { COSY of 6-O-Benzoyl-1- } \mathrm{N} \text {-tert-butoxycarbonyl-3,2',6'-triazido-3',4'-dideoxy-3'- } \\
\text { enoneamine (6) }\end{array}$ & $\mathrm{S} 21$ \\
\hline $\begin{array}{l}{ }^{1} \mathrm{H} \text { NMR of 5-O-(4-Azido-4,6-dideoxy- } \beta \text {-D-glucopyranosyl)-1- } N \text {-tert-butoxycarbonyl-3,2',6'- } \\
\text { triazido-3',4'-dideoxy-3'-enoneamine (8) }\end{array}$ & S22 \\
\hline $\begin{array}{l}{ }^{13} \mathrm{C} \text { NMR of 5-O-(4-Azido-4,6-dideoxy- } \beta \text {-D-glucopyranosyl)-1- } N \text {-tert-butoxycarbonyl-3,2',6'- } \\
\text { triazido-3',4'-dideoxy-3'-enoneamine (8) }\end{array}$ & $\mathrm{S} 23$ \\
\hline $\begin{array}{l}{ }^{1} \mathrm{H} \text { NMR of 5-O-(4-Azido-4,6-dideoxy- } \beta \text {-D-glucopyranosyl)-1- } N \text {-[(S)-4- } \\
\text { (benzyloxycarbonylamino)-2-hydroxybutanoyl]-3,2',6'-triazido-3',4'-dideoxy-3'-enoneamine } \\
\text { (10) }\end{array}$ & S24 \\
\hline $\begin{array}{l}{ }^{13} \mathrm{C} \text { NMR of 5-O-(4-Azido-4,6-dideoxy- } \beta \text {-D-glucopyranosyl)-1- } N \text { - }[(\mathrm{S})-4- \\
\text { (benzyloxycarbonylamino)-2-hydroxybutanoyl]-3,2',6'-triazido-3',4'-dideoxy-3'-enoneamine } \\
\text { (10) }\end{array}$ & $\mathrm{S} 25$ \\
\hline${ }^{1}$ H NMR of Pyrankacin & S26 \\
\hline${ }^{13}$ C NMR of Pyrankacin & $\mathrm{S} 27$ \\
\hline
\end{tabular}




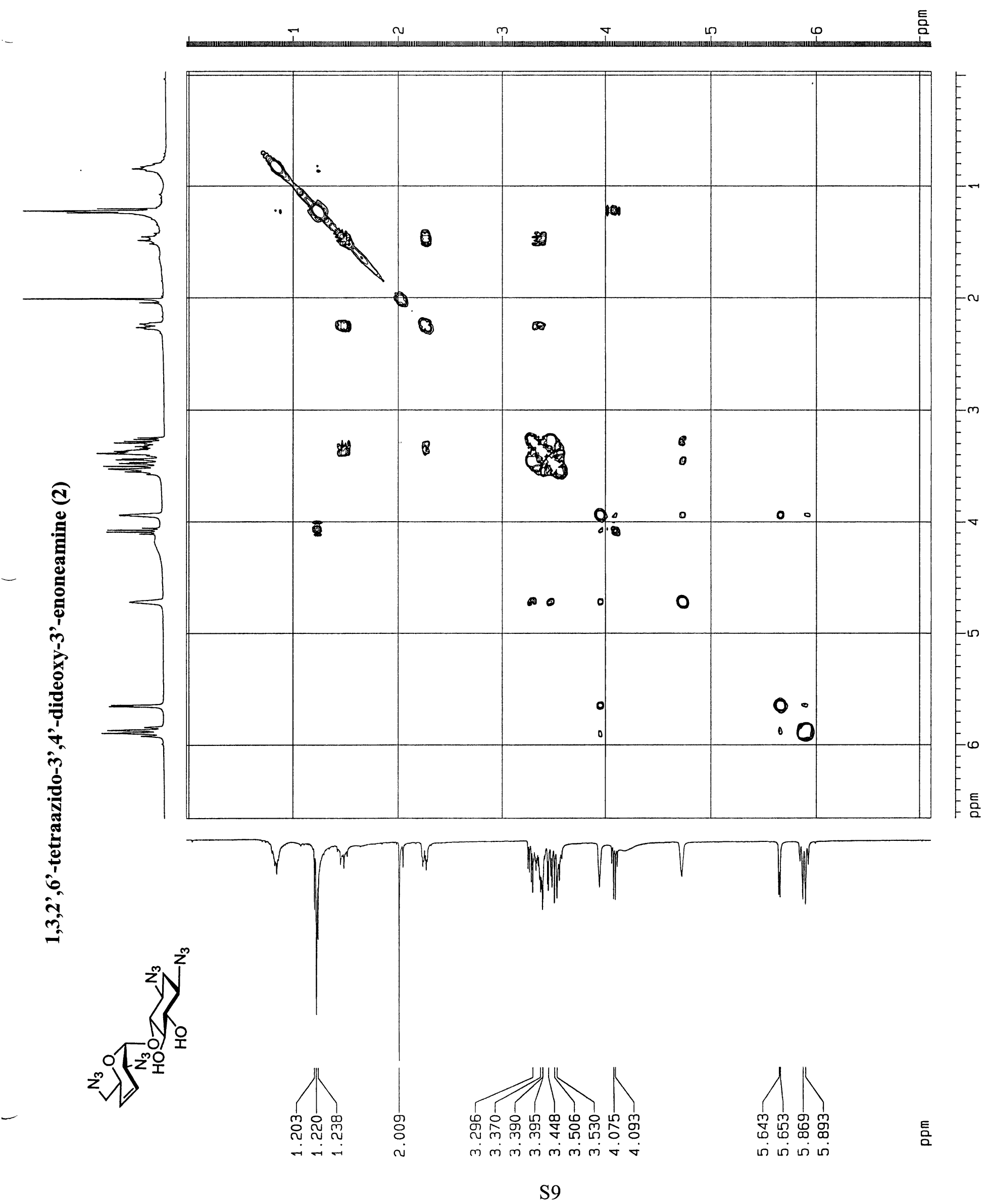



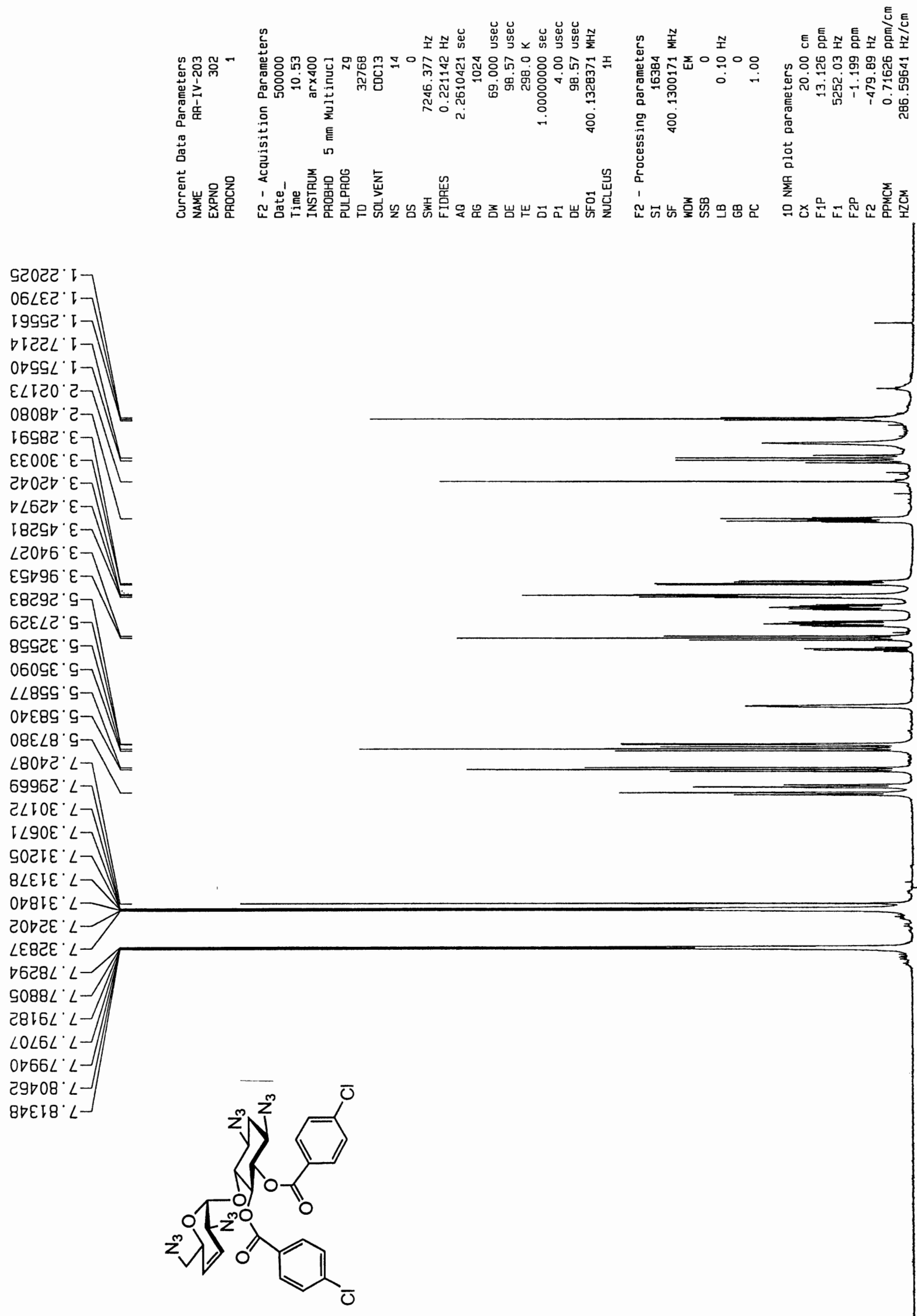


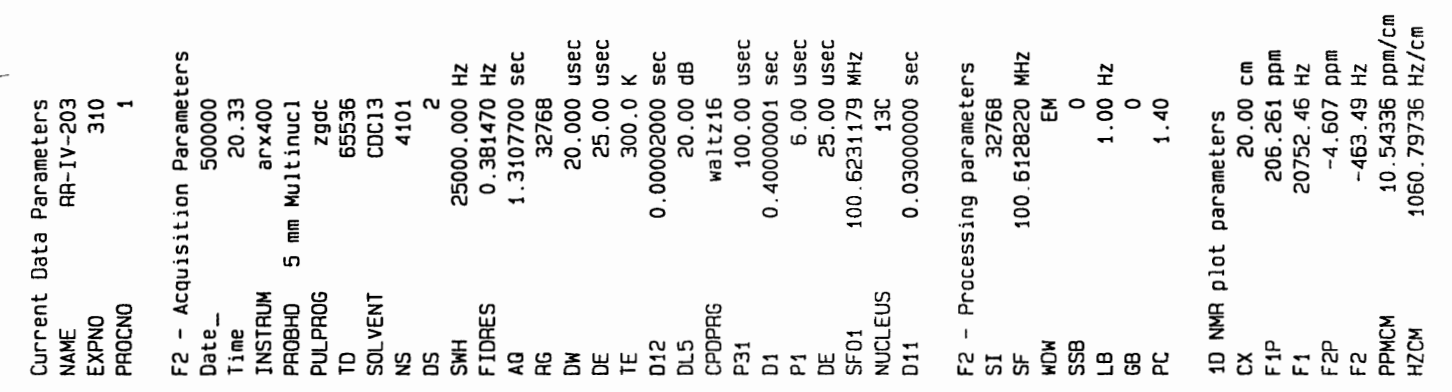

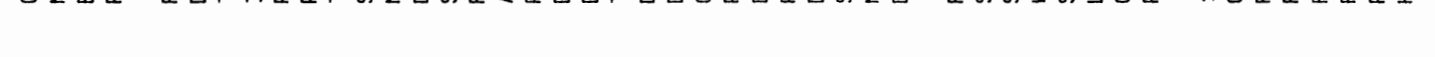

G99.EI

$695 \cdot 62-$

วนด. เE -
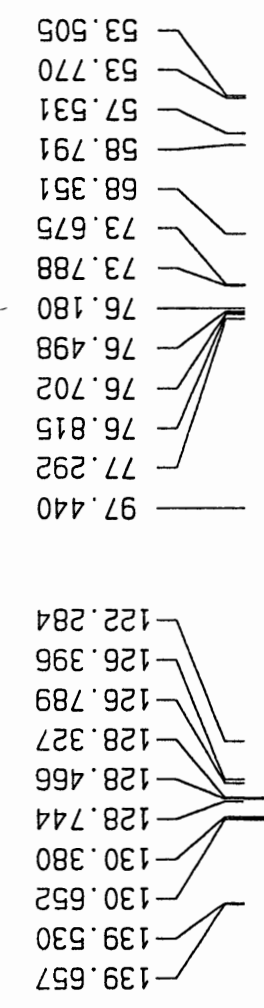

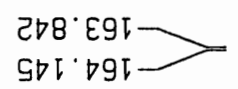

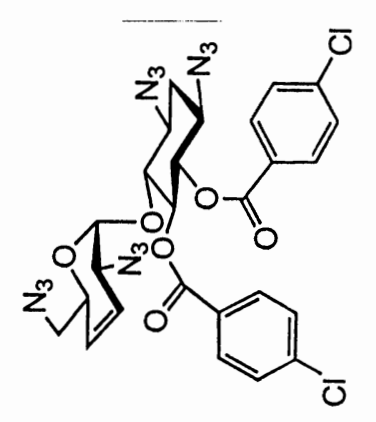



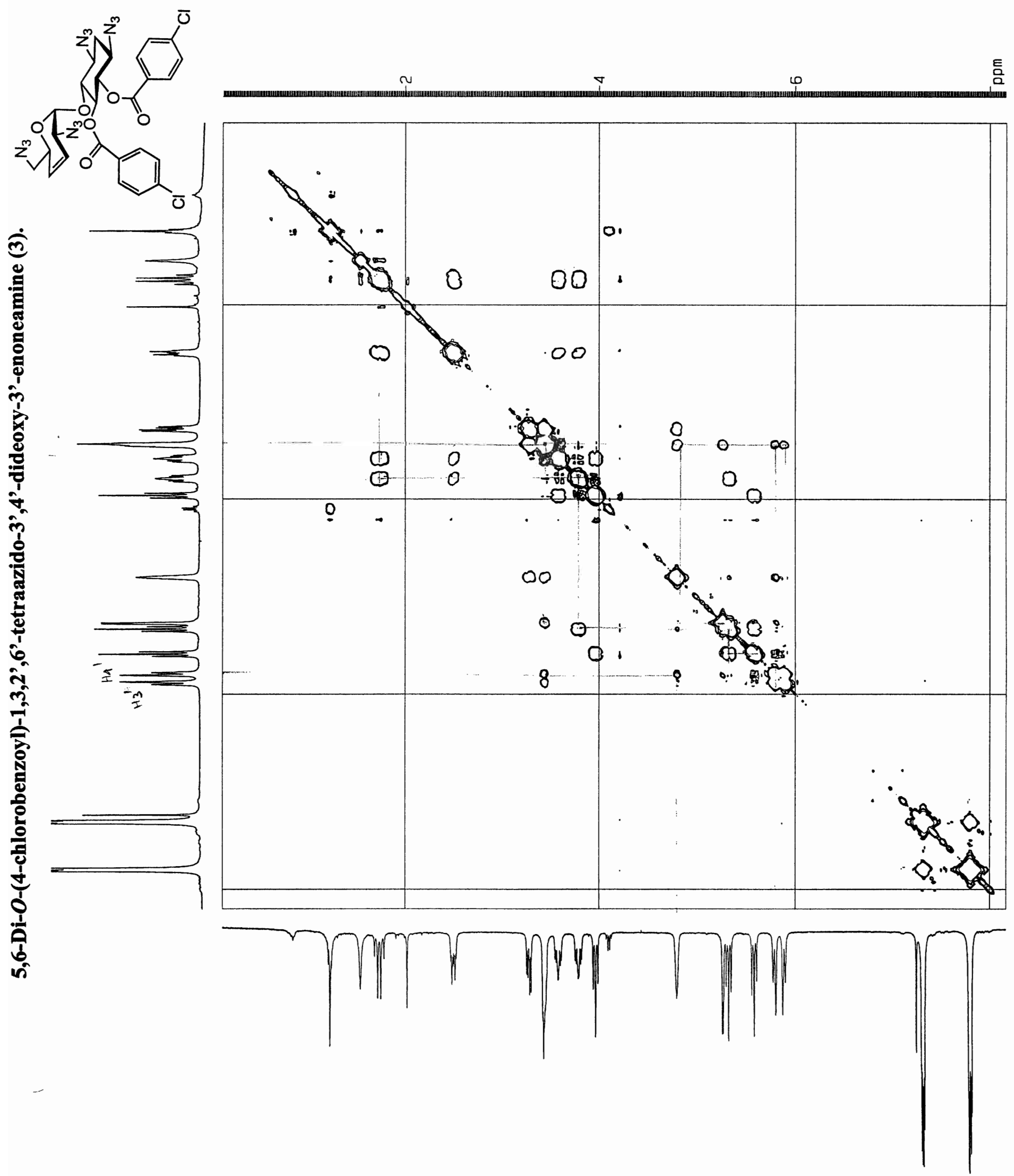

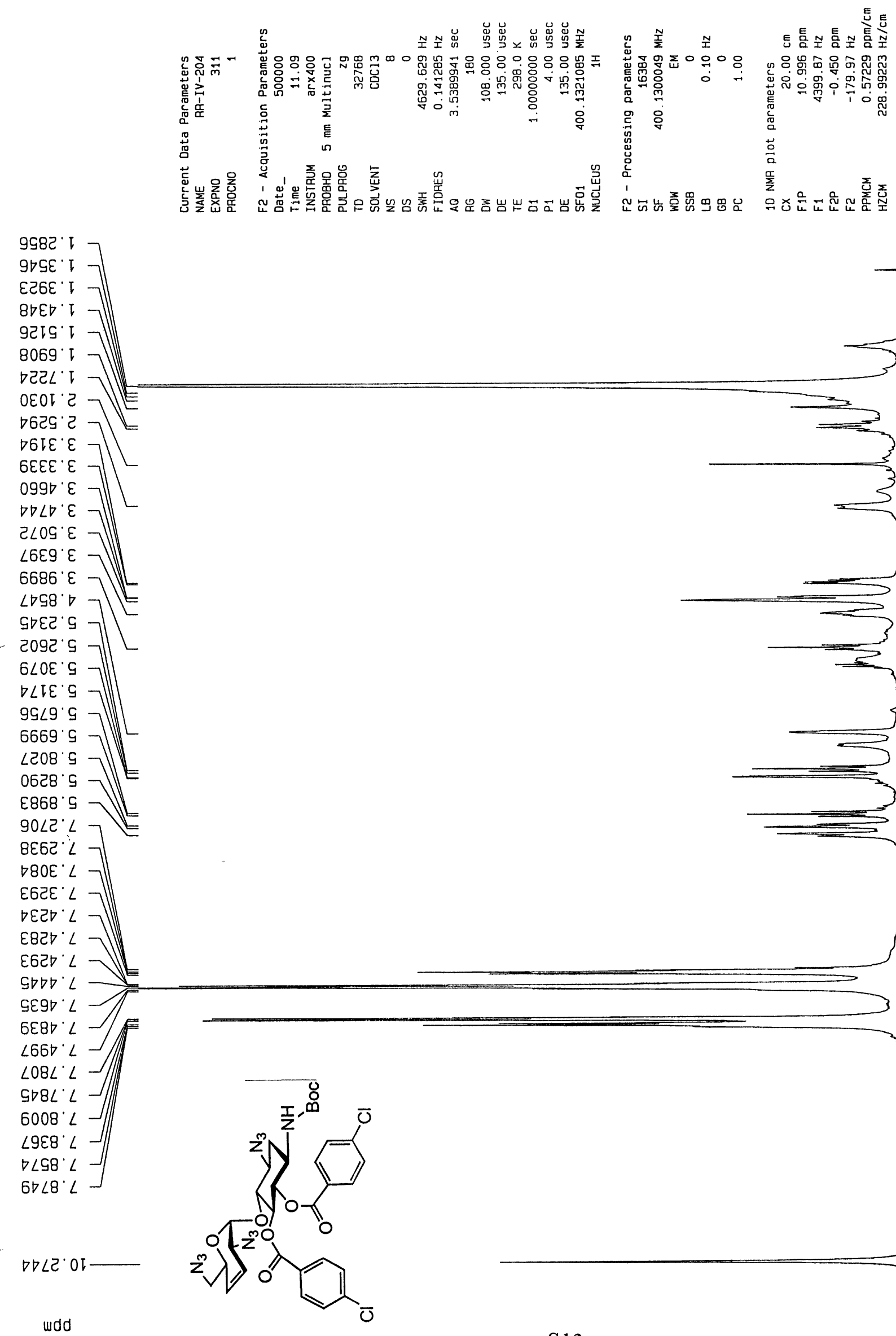

wdd
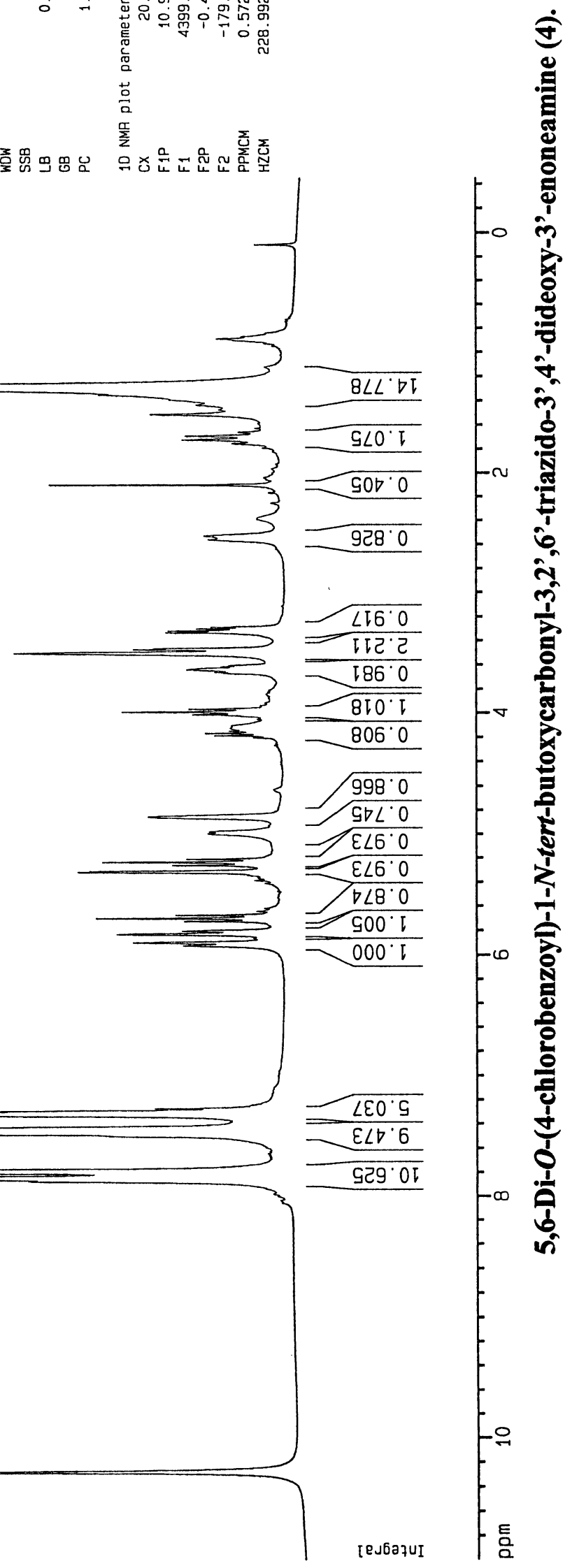


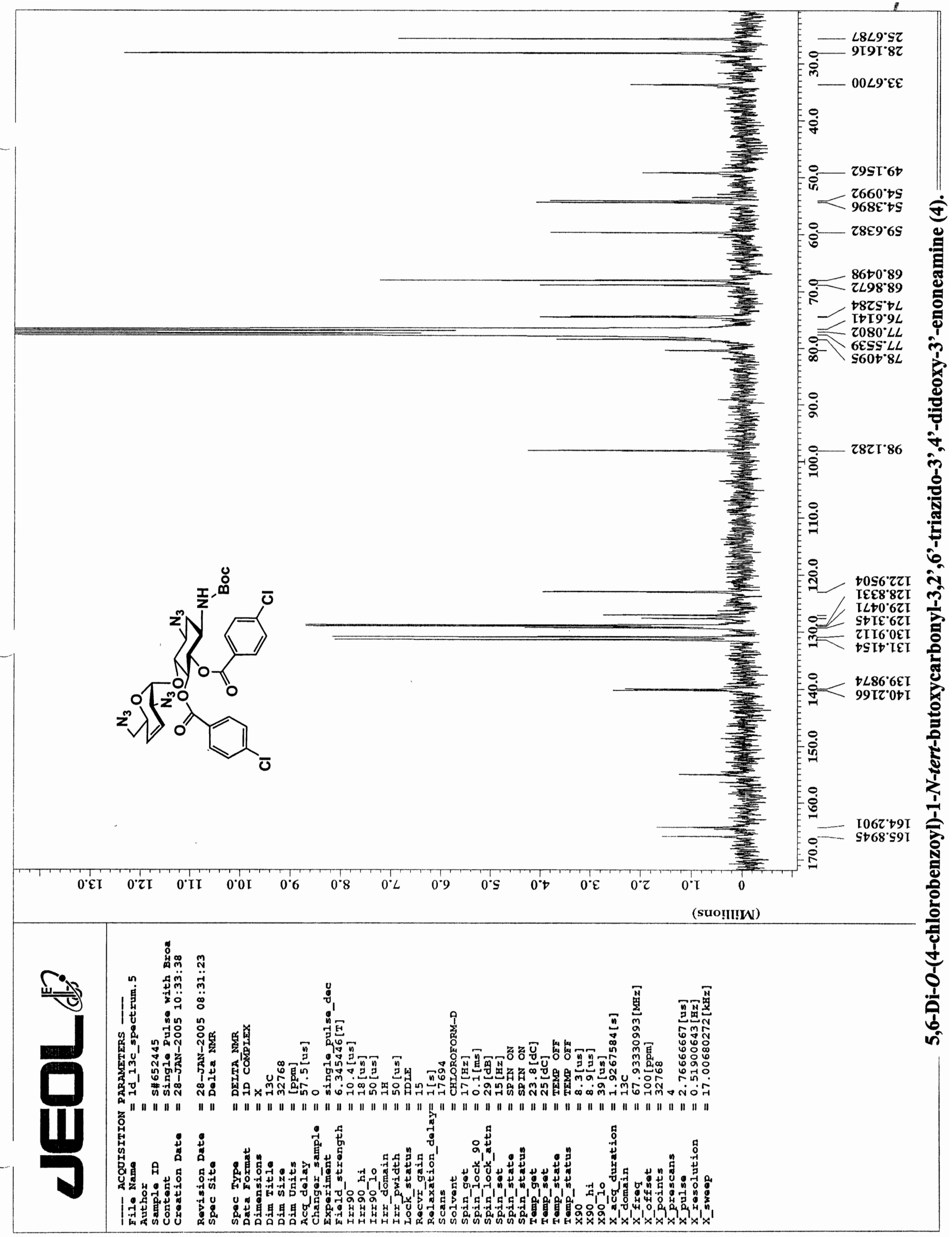



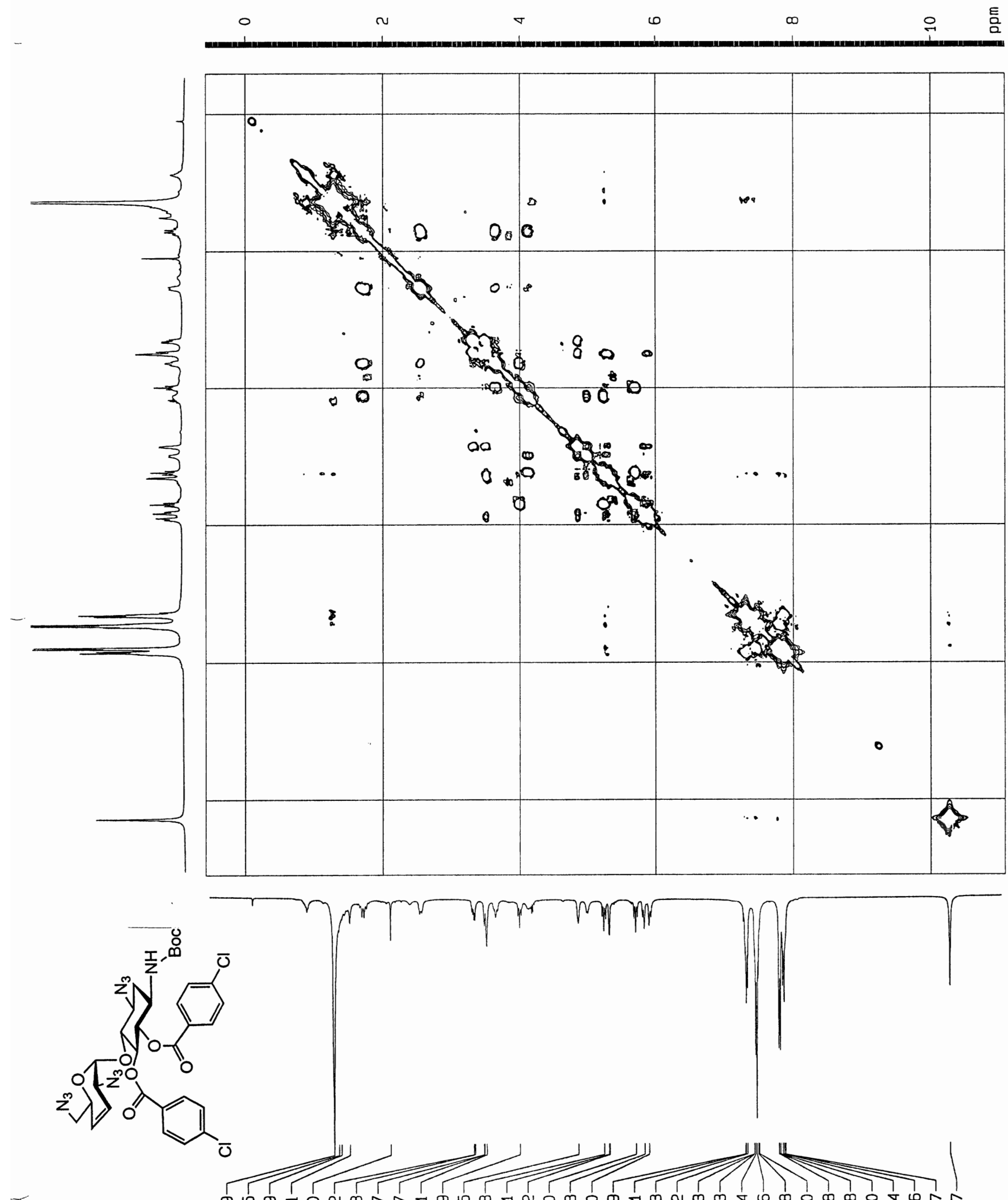

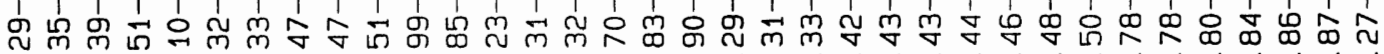

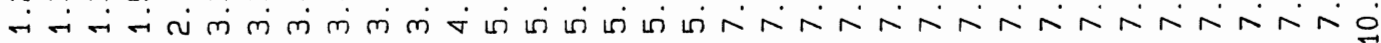



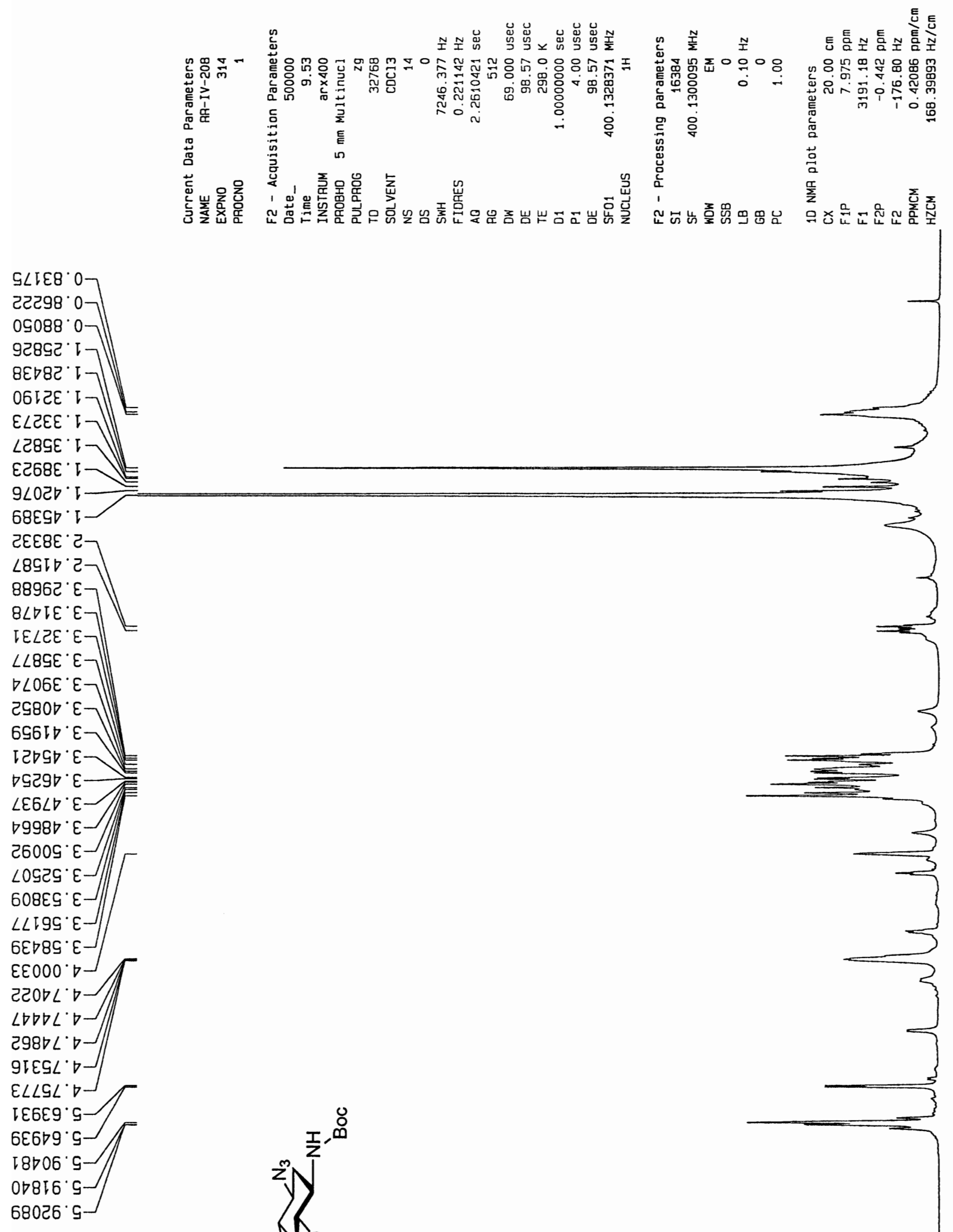

8669ट $L$

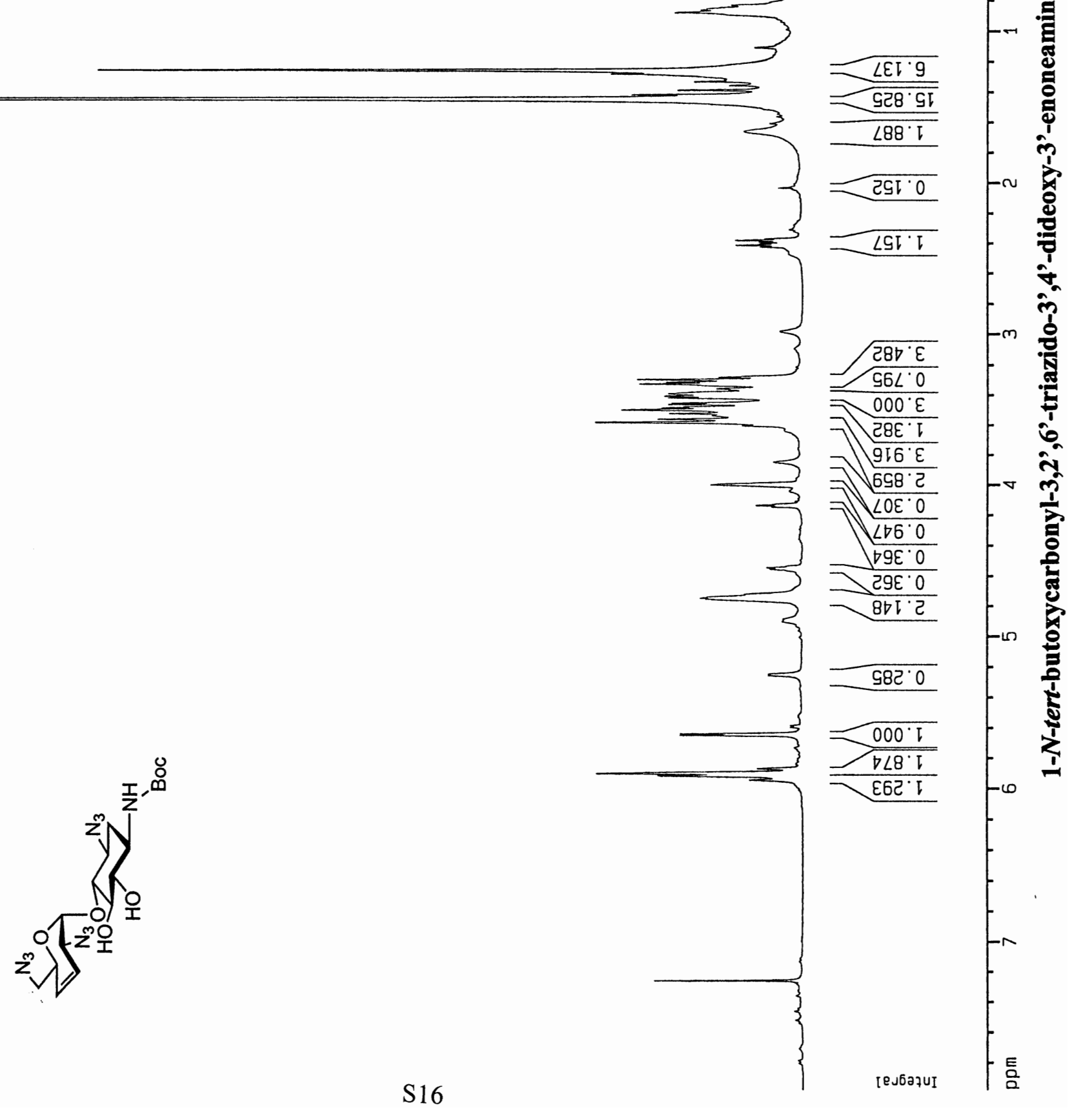



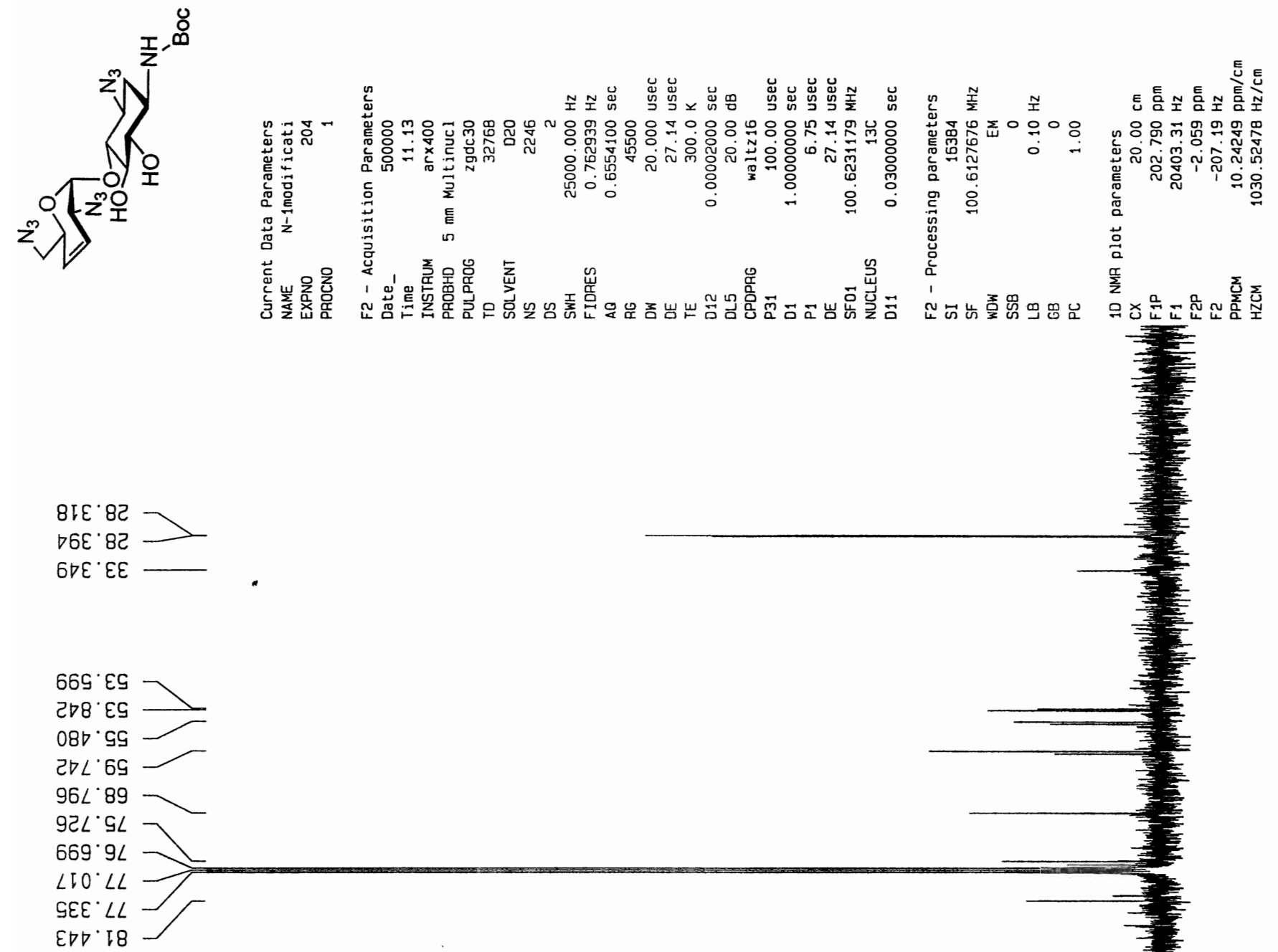

E8E' $\angle 6$ I $\triangle 96$

609. टटा-

98L टटा

$\checkmark 9 \nabla^{\circ} 621$

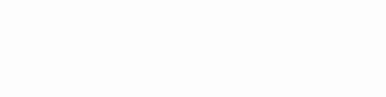




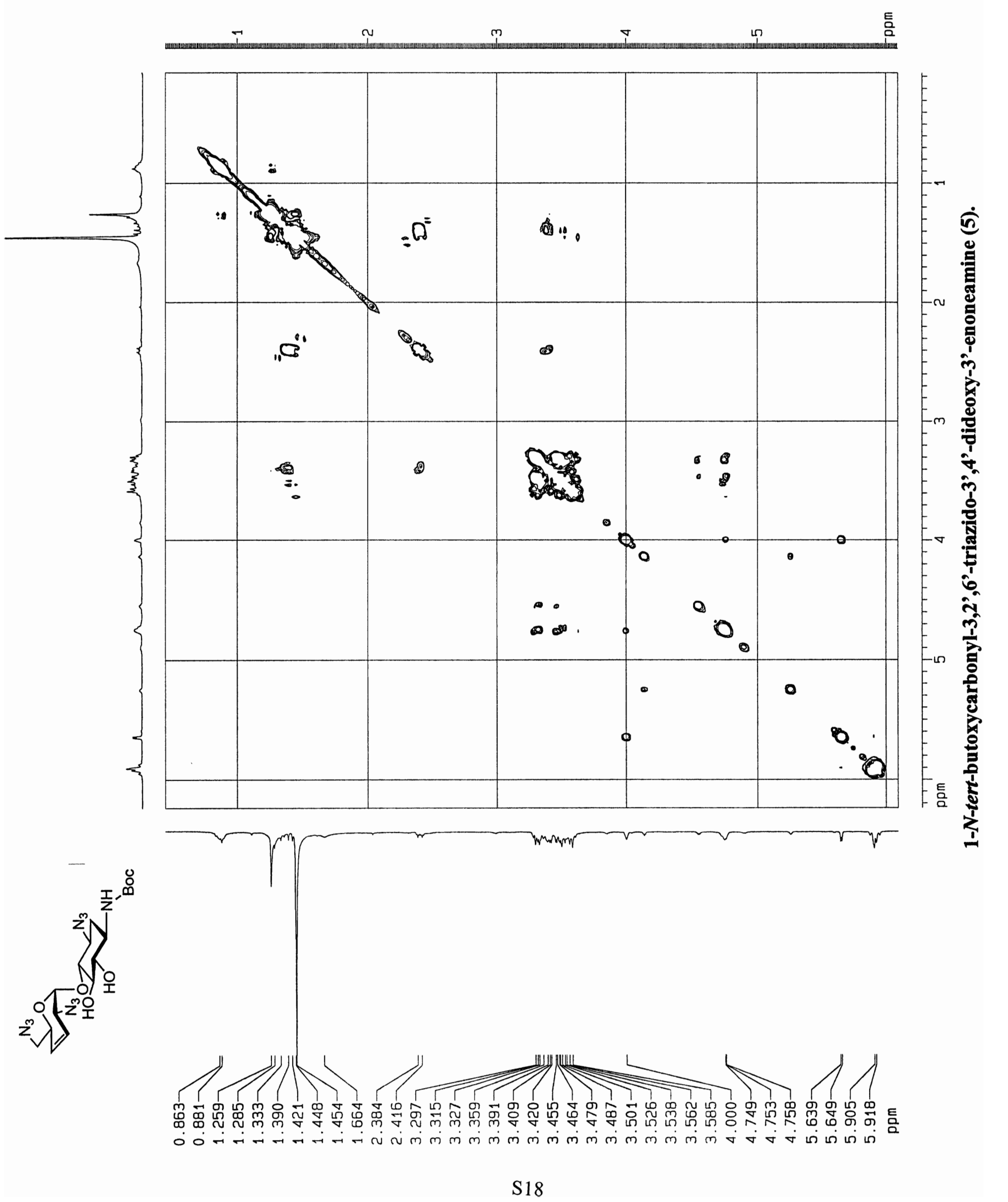



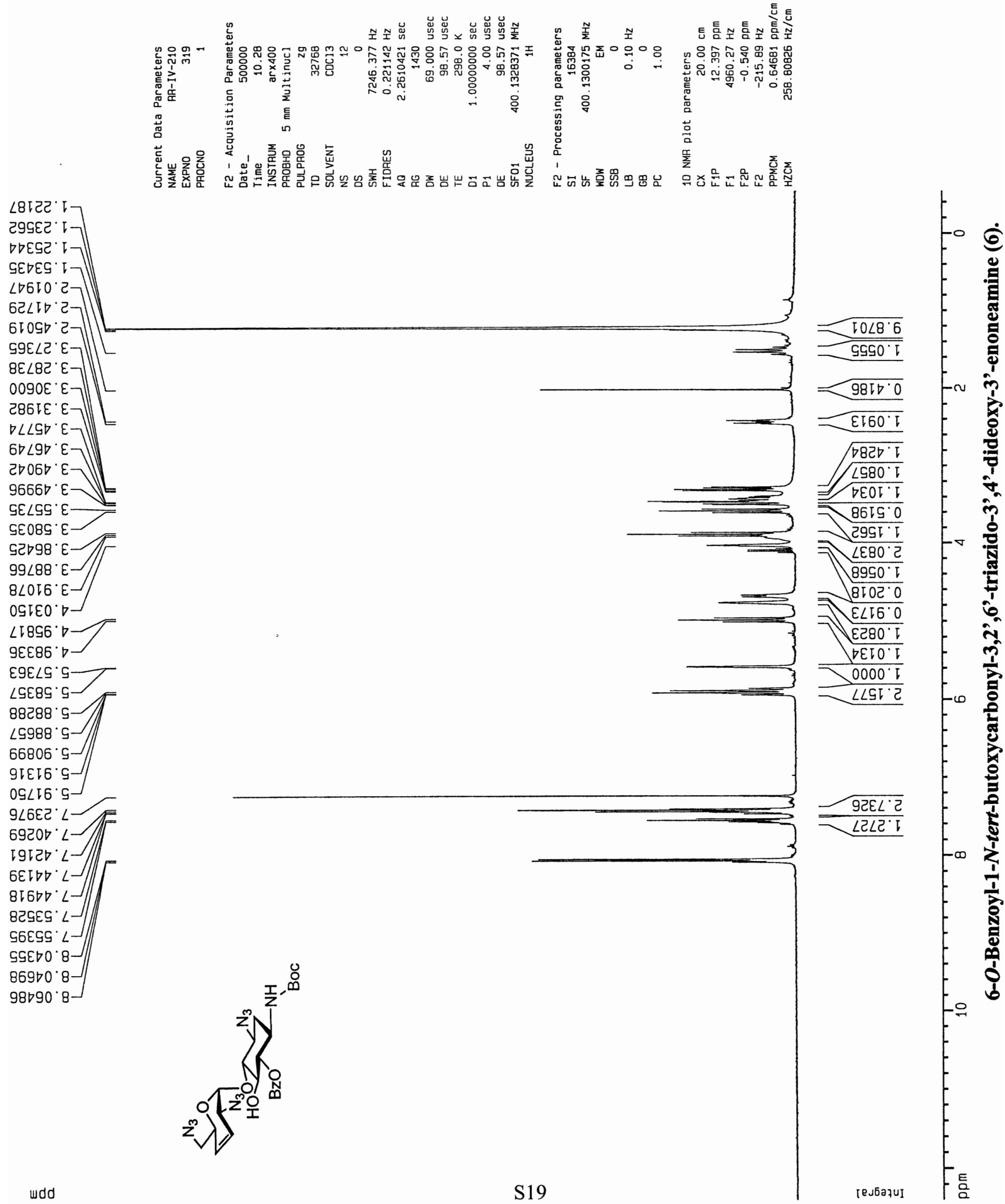


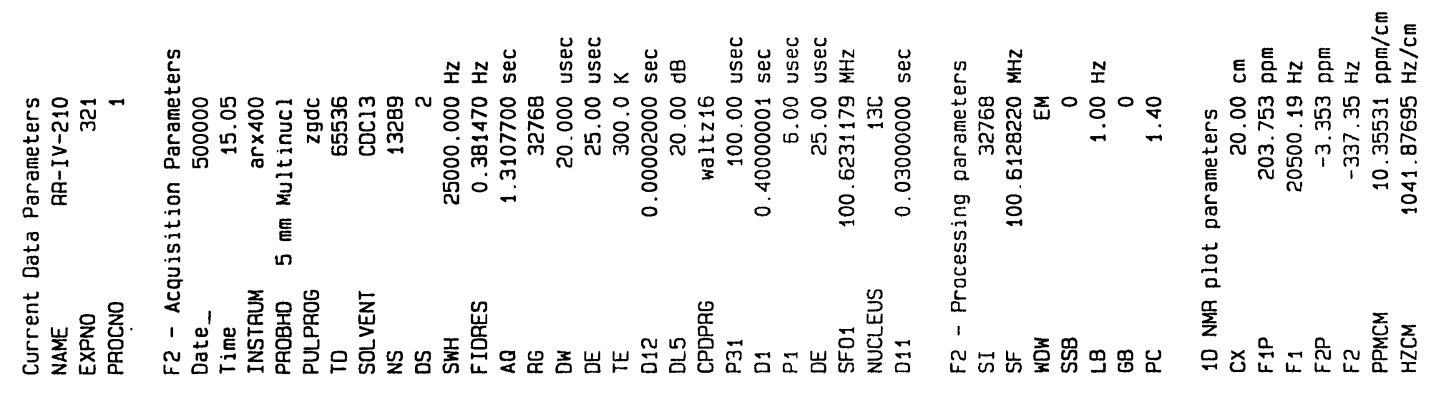

$8 \nabla 9^{\circ} \angle 2$

OEट ' $\varepsilon \varepsilon$

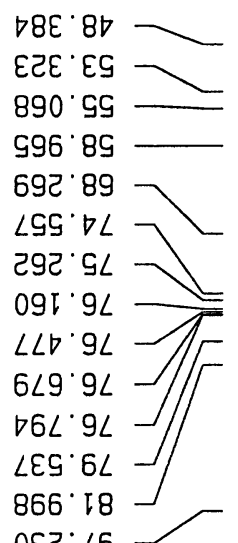

OEट ' $\angle 6$

OEГ'ટटГ

$668^{\circ} \angle ट \downarrow$

टE6 ' $\angle 2 T>$

$\triangle 0 \angle 821$

$\angle 06^{\circ} 82$ Г

ट $\angle 0^{\circ} 62$

SES 62

टह9 6टा

ᄂ $\angle 6^{\circ}$ टहा

OSO $E \varepsilon \digamma-$

$699^{\circ} \nabla 9 F$

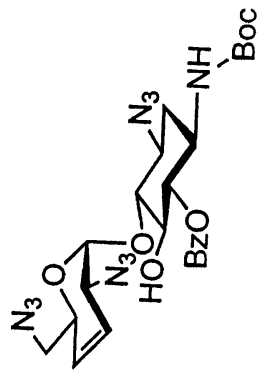

Г99.99 


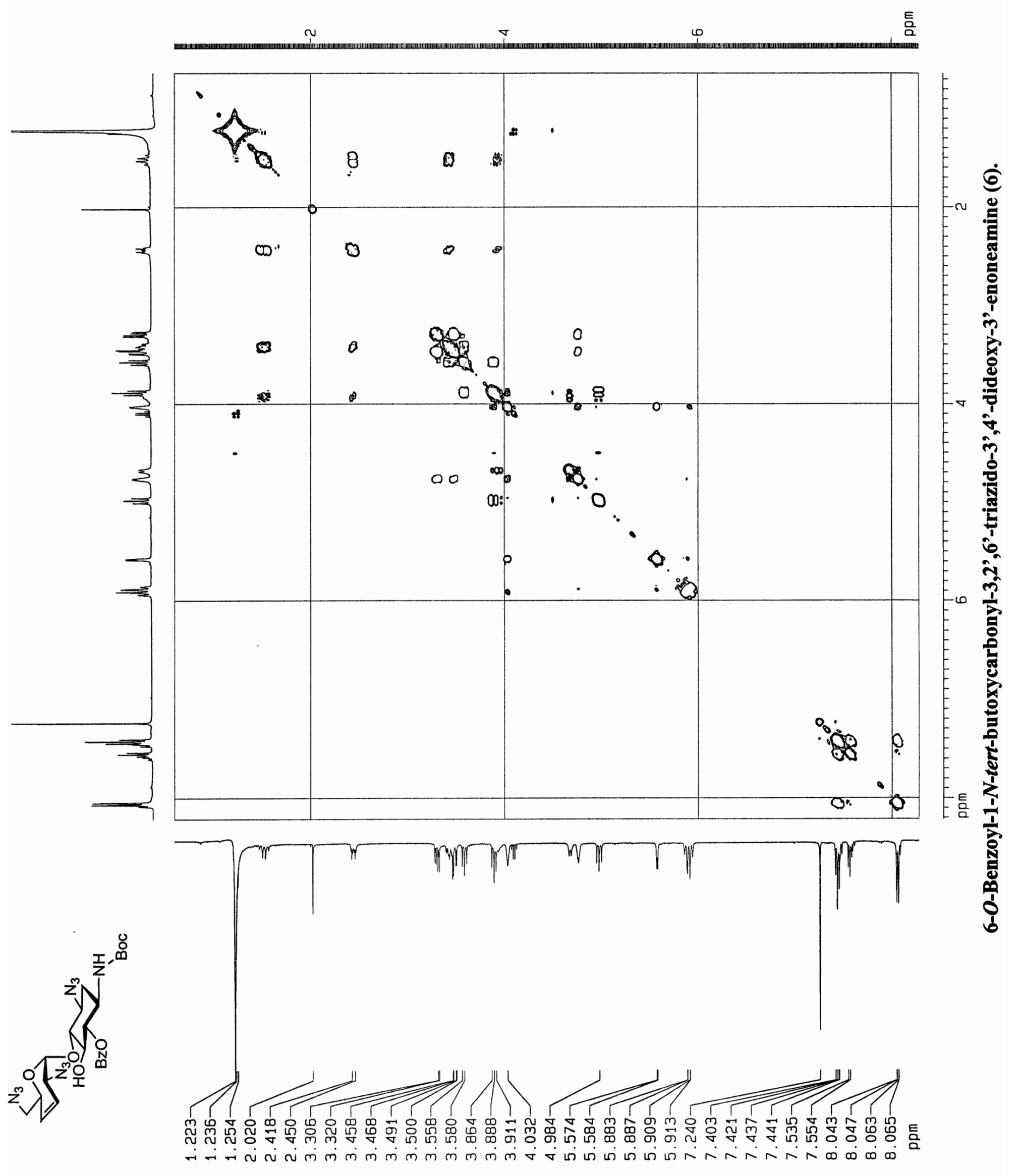



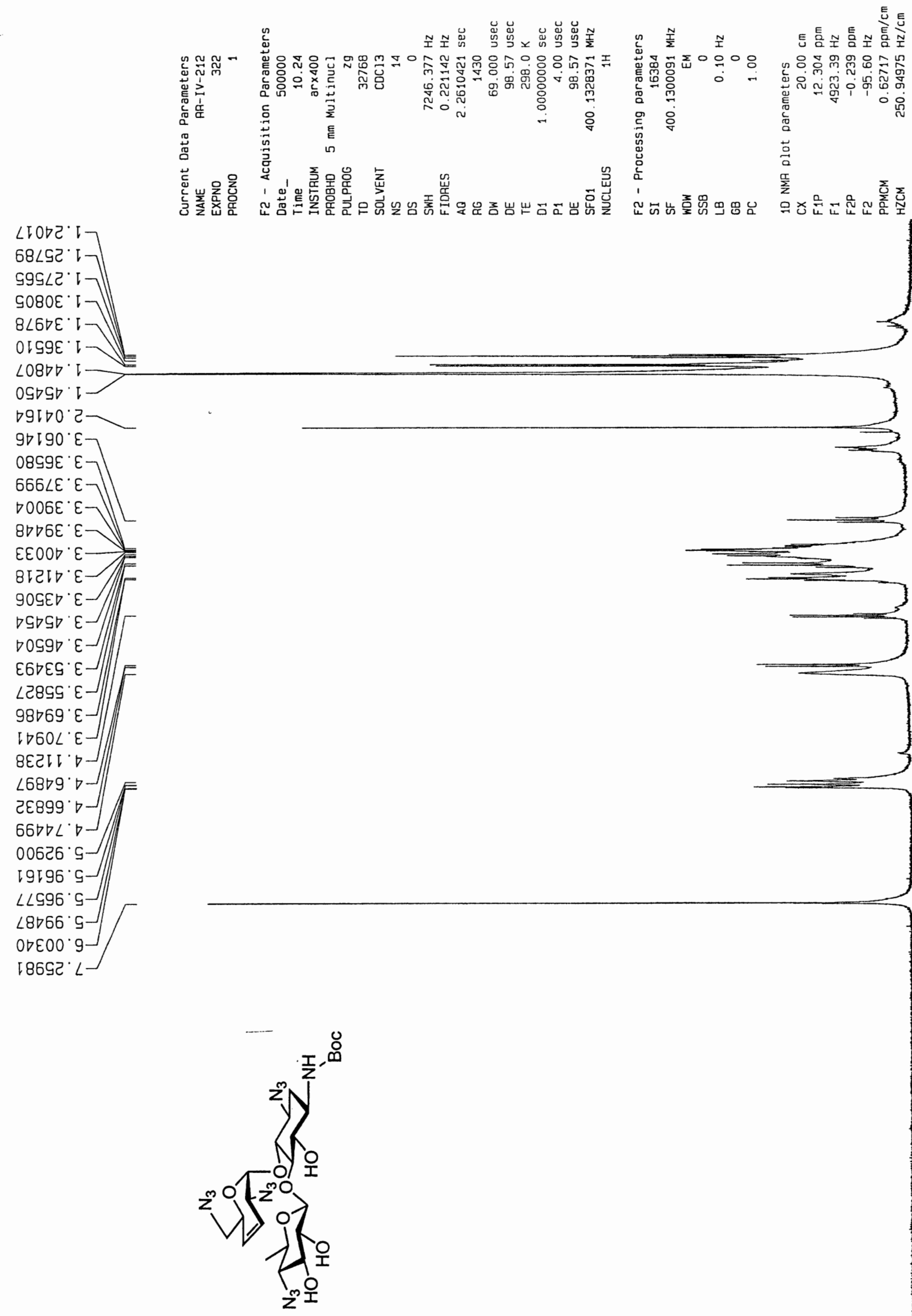


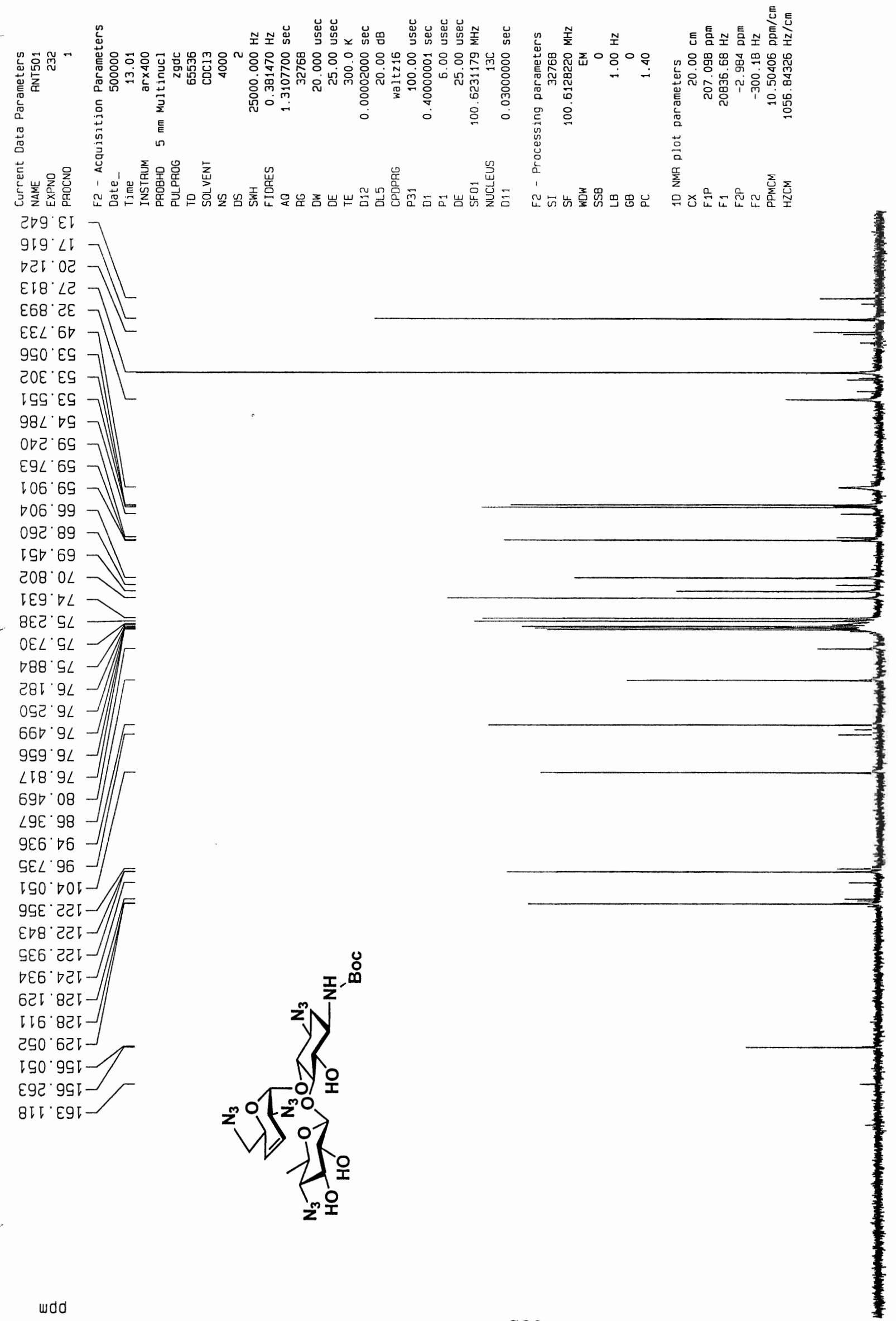



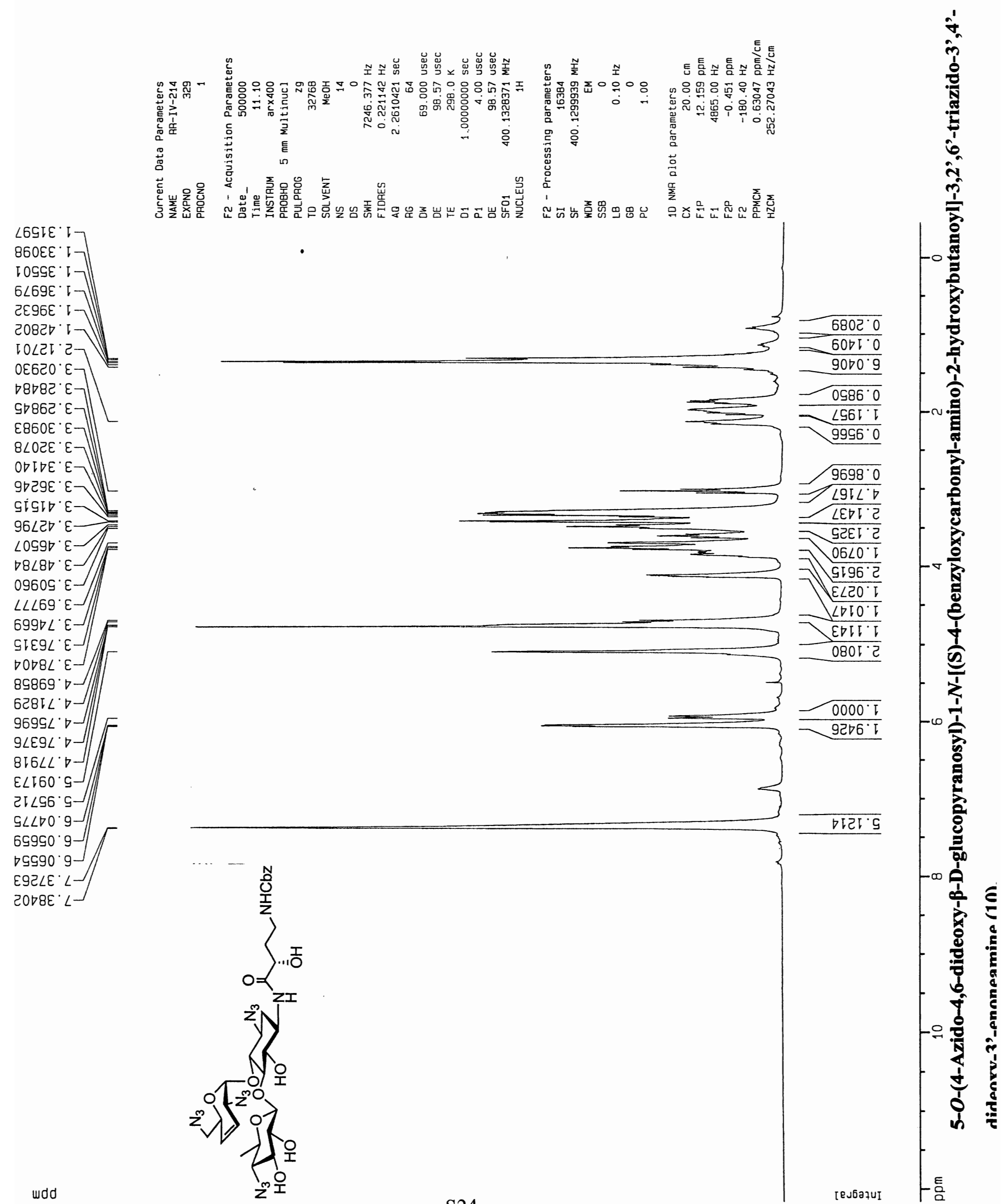


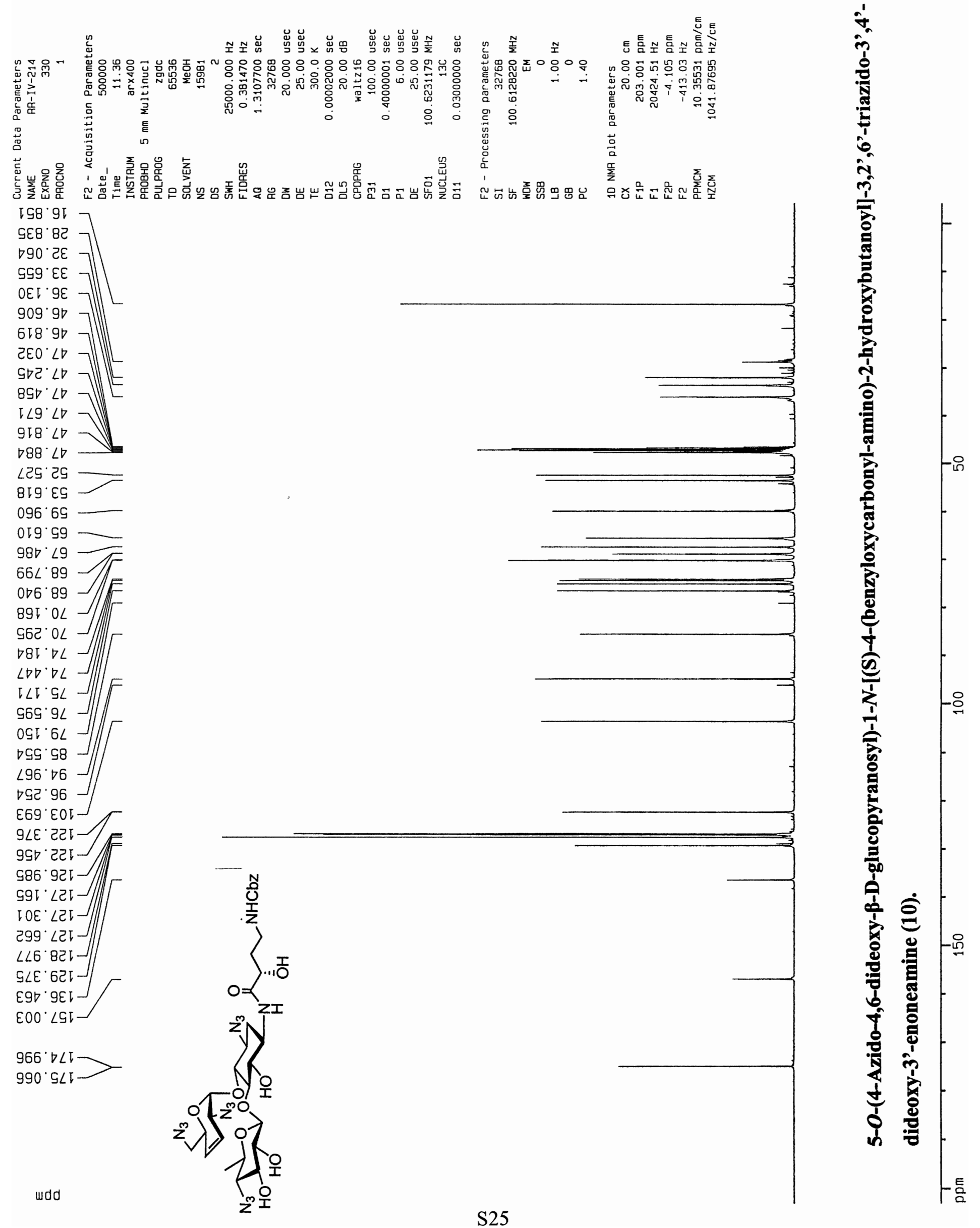



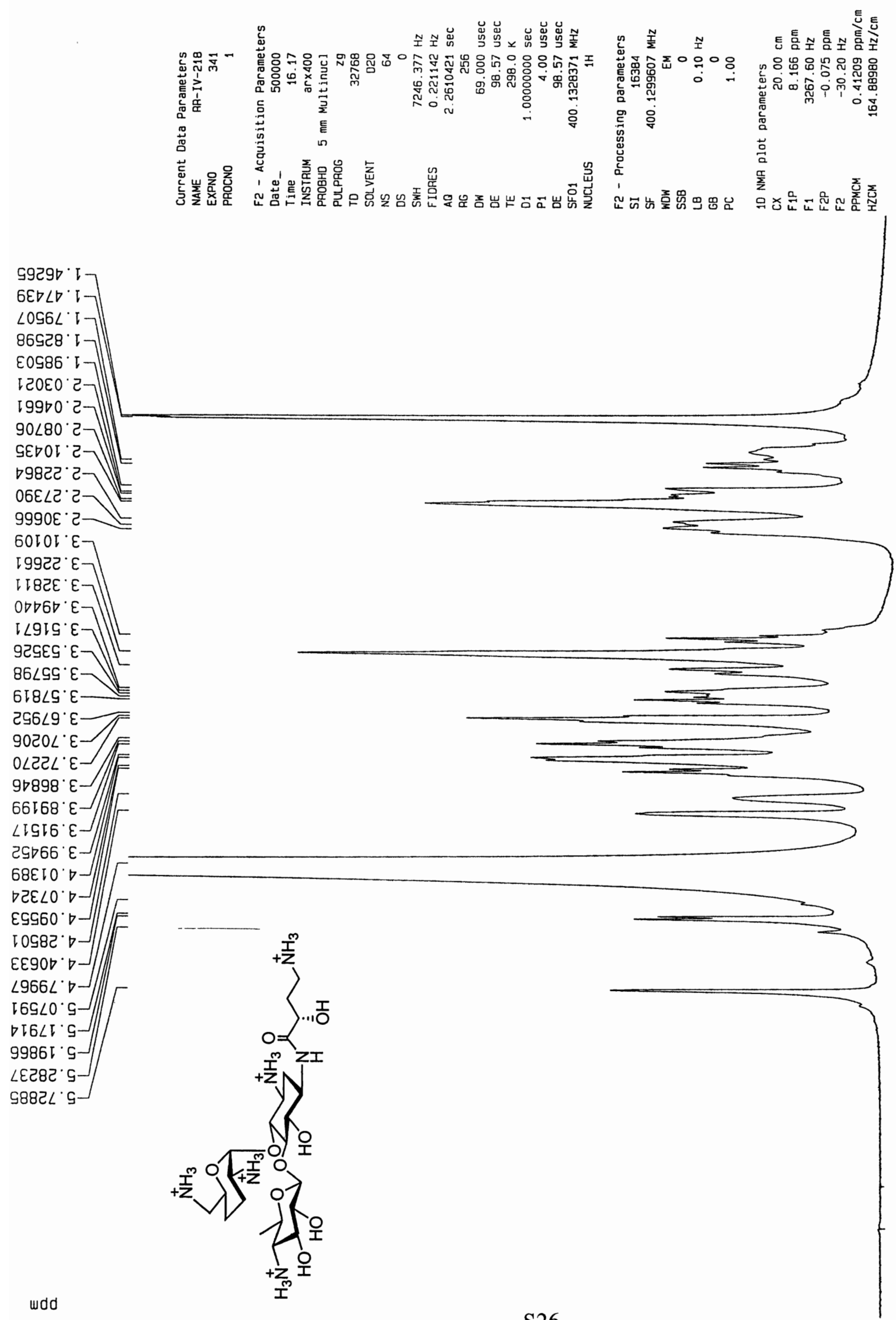


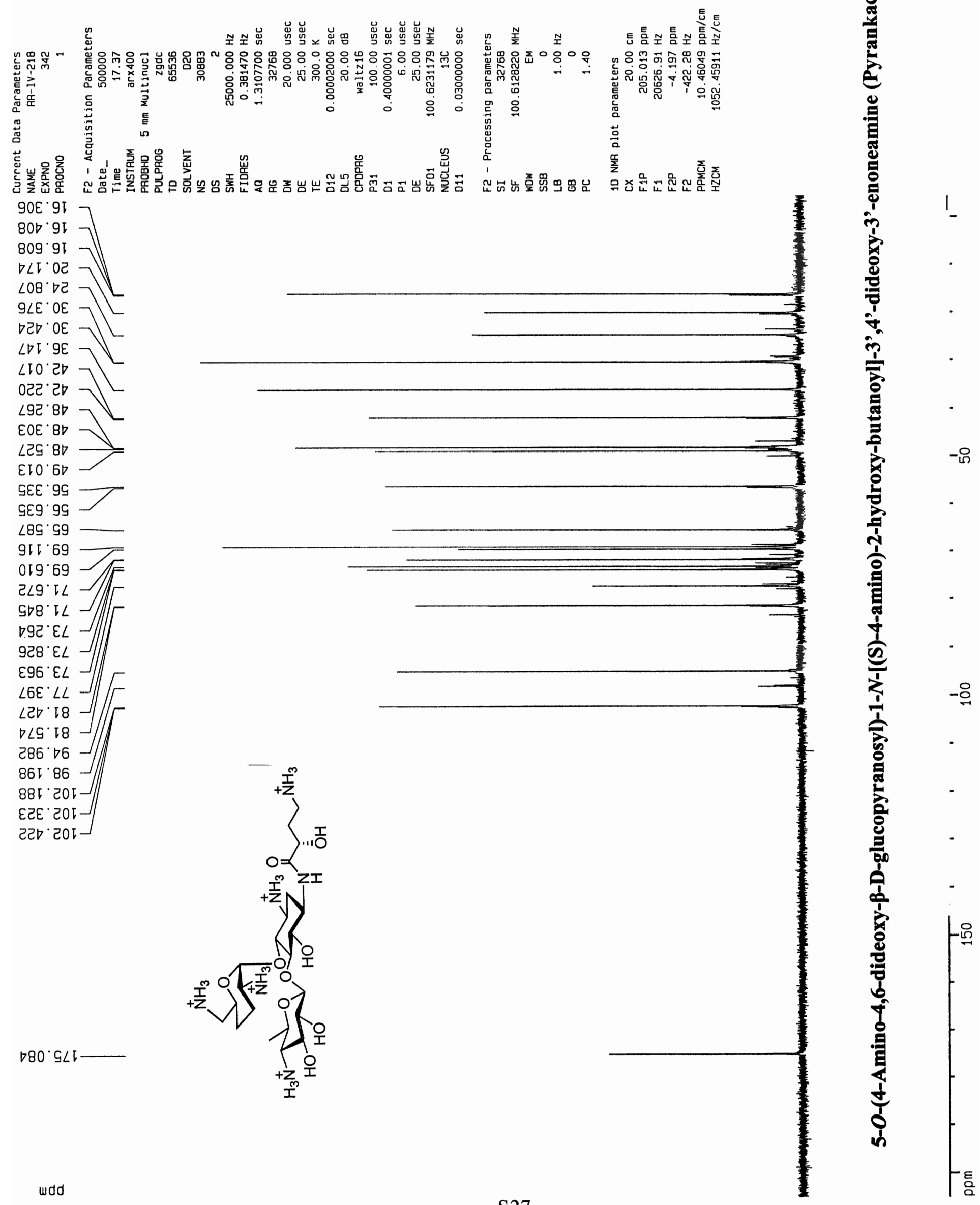




\section{Molecular Modeling of Pyrankacin}

The structure is based on the studies of published X-ray structure published. ${ }^{3}$ The AHB side chain resides in the same position as other AHB-containing aminoglycosides or aminoglycoside derivatives.

Figure A. Binding of pyrankacin toward the fragmen tof A-site decoding region of 16S rRNA. The AHB side chain locates at the same position as other AHB-containing aminoglycosides.
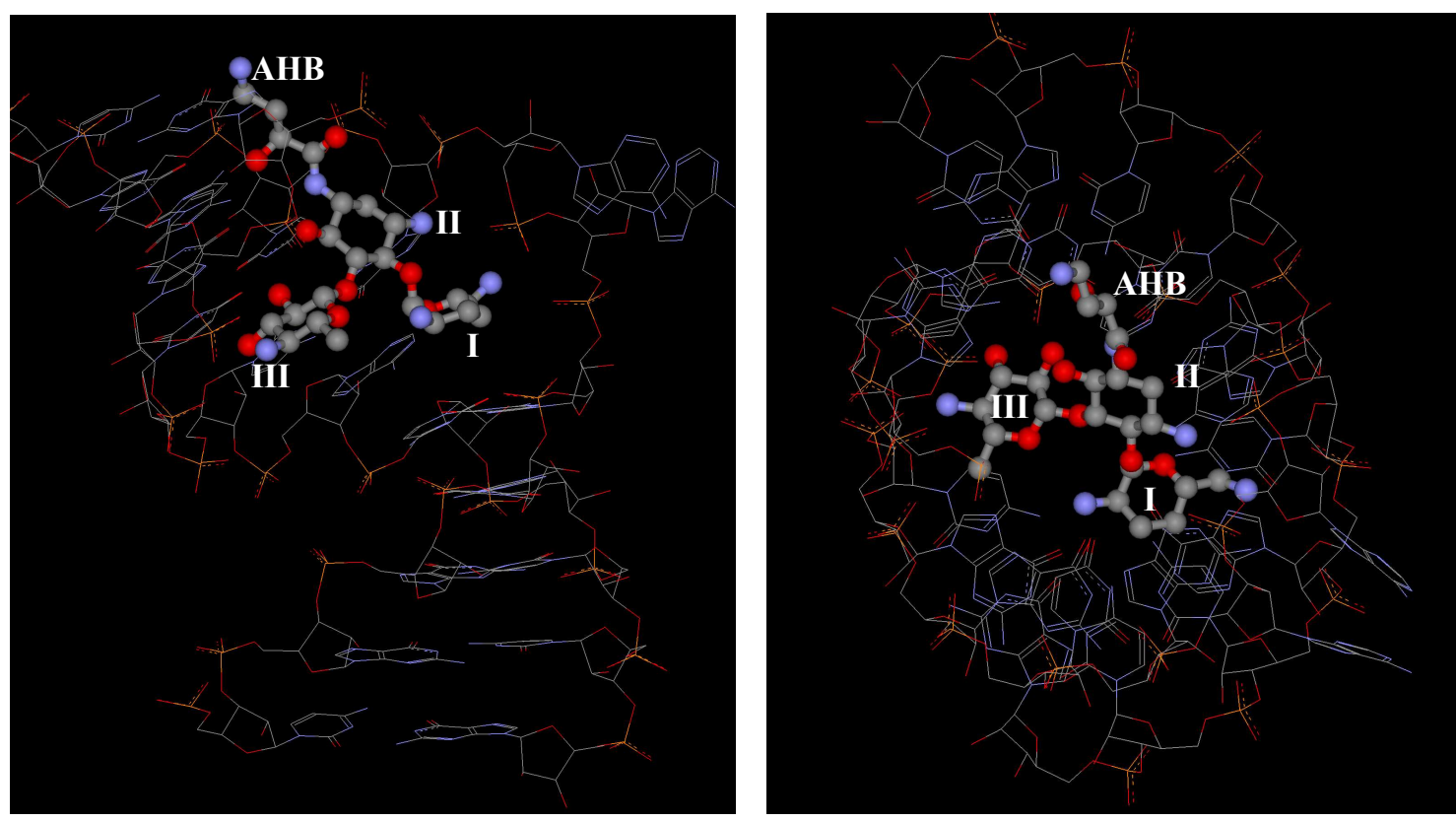
Figure B. The modeled structure of Pyrankacin/Kanamycin kinase (APH(3')-III) complex, based on PDB 1L8U structure ${ }^{4 b}$. Residues causing steric hinderance with the 2-hydroxy-4aminobutyric chain colored black.

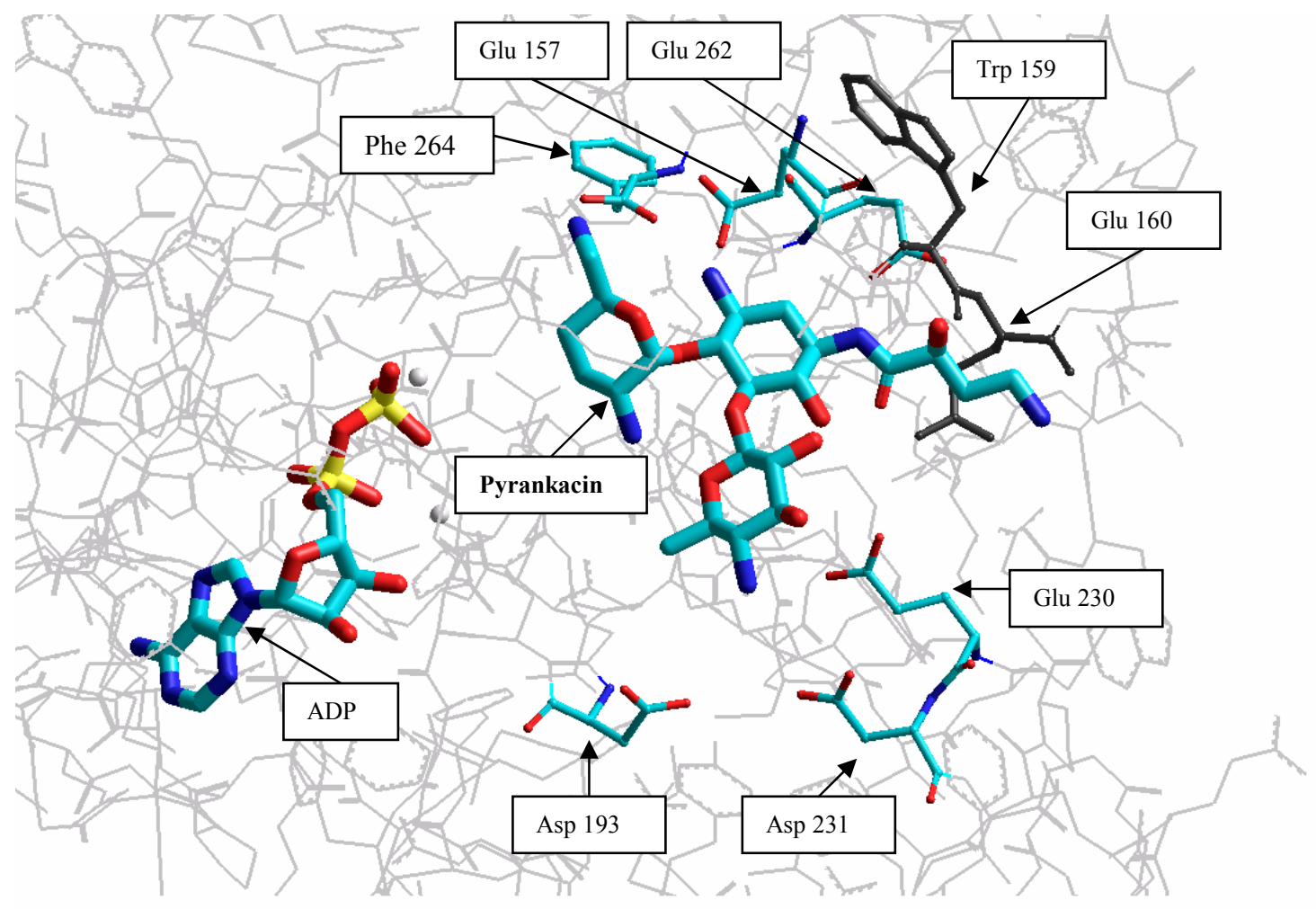


Figure C. The modeled structure of a complex of pyrankacin with Aminoglycoside 2'-NAcetyltransferase from Mycobacterium tuberculosis, based on PDB 1M4D structure. ${ }^{4 \mathrm{c}}$ Residues causing steric hinderance with the 2-hydroxy-4-aminobutyric chain colored black.

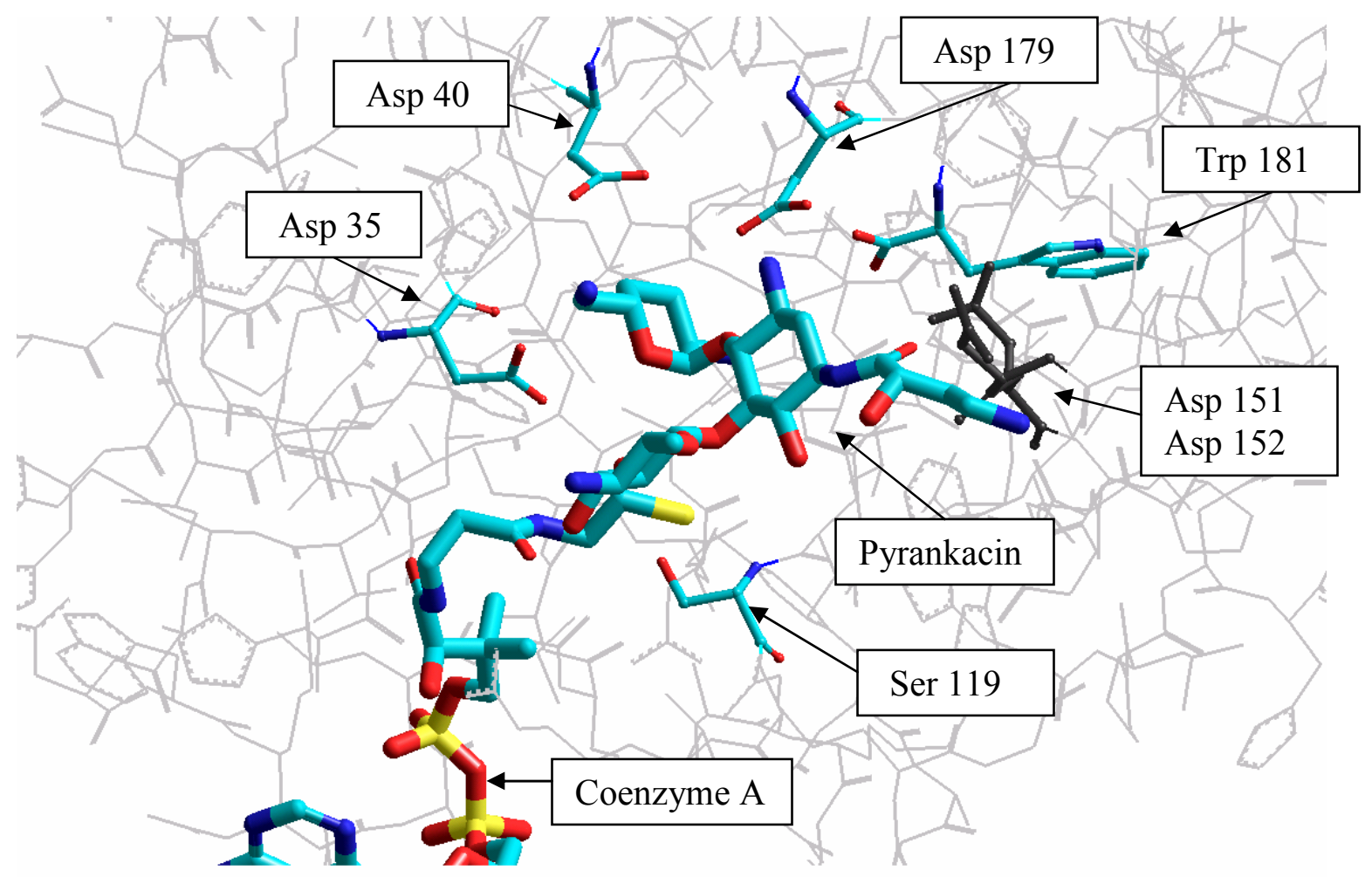




\section{References}

1. Li, J.; Chen, H.-N.; Chang, H.; Wang, J.; Chang, C.-W. T. Org. Lett. 2005, 7, 3061-3064.

2. Rai, R.; Chen, H, -N.; Chang, C, -W. T.; J. Carbohydr Chem. 2005, 24, 131-143.

3. The procedure was modified from Methods for Dilution Antimicrobial Susceptibility Testing for Bacteria that Grow Aerobically. Approved standard M7-A5, and Performance Standards for Antimicrobial Disk Susceptibility Tests. Approved standard M2-A7, National Committee for Clinical Laboratory Standards, Wayne, PA.

4. (a) Russell, R. J. M.; Murray, J. B.; Lentzen, G.; Haddad, J.; Mobashery, S. J. Am. Chem. Soc., 2003, 125, 3410-3411. (b) Fong, D. H., Berghuis, A. M. EMBO J., 2002, 21, 23232331. (c) Vetting, M. W., Hegde, S. S., Javid-Majd, F., Blanchard, J. S., Roderick, S. L. Nat.Struct.Biol. 2002, 9, 653. 